Universität Bielefeld Faculty of Business Administration and Economics

\title{
Spatial labor market frictions and economic convergence: policy implications from a heterogeneous agent model
}
H. Dawid
P. Harting
M. Neugart 


\title{
Spatial labor market frictions and economic convergence: policy implications from a heterogeneous agent model*
}

\author{
H. Dawid P. Harting; and M. Neugart $^{\ddagger}$ \\ February 2013
}

\begin{abstract}
This paper studies the effectiveness of different types of cohesion policies with respect to convergence of regions. A two-region agentbased macroeconomic model is used to analyze short-, medium- and long-term effects of policies improving human capital and fostering adoption of technologies in lagging regions. With fully integrated labor markets the human capital policy positively affects the economically stronger region but reduces production in the targeted weaker region. Subsidies for high technology investment in the weaker region have a positive local output effect and a negative effect on the neighboring region, thereby fostering convergence. When labor markets are not integrated both policies support convergence.
\end{abstract}

Keywords: cohesion policies, technology adoption, skill complementarity, agent-based model, regional economics

JEL Classification: C63, O33

*The authors would like to thank Göran Kauermann for great help in the statistical analysis and Simon Gemkow and Sander van der Hoog for fruitful discussions. The paper has benefited from comments and suggestions by participants of the following Workshops, Conferences and Research Seminars: Computing in Economics and Finance 2012 (Prague), WEHIA 2012 (Paris), Workshop on Agent-Based Modeling in Economics at the Latsis Symposium 2012 (Zurich), Workshop on Micro-Foundations and Systemic Impacts 2012 (Ancona), Seminars at Bielefeld University, University of Amsterdam, OFCE Sophia Antipolis, University of Bayreuth, University of Bamberg. Financial support under the COST Action IS1104: 'The EU in the new complex geography of economic systems: models, tools and policy evaluation' is gratefully acknowledged.

${ }^{\dagger}$ Department of Business Administration and Economics and Institute of Mathematical Economics, Bielefeld University, Germany

${ }^{\ddagger}$ Department of Business Administration and Economics, Bielefeld University, Germany

$\S$ Department of Law and Economics, Technical University of Darmstadt, Germany 


\section{Introduction}

There is a persistent gap in terms of economic performance and growth between different European regions. Despite large efforts to integrate European economies the problem of real convergence in the European Union (EU) area is to a large degree still unsolved and the effectiveness of the cohesion policy measures is contested (see e.g. Boldrin and Canova (2001), Cappelen et al. (2003), Aiello and Pupo (2012)).

EU policies to facilitate convergence of per capita income and productivity refer to two broad areas. First, there is the funding of regional policies. The European Fund for Regional Development (ERDF), the European Social Fund (ESF), the Cohesion Fund (CF), and the Instrument for Pre-Accession Assistance (IPA) are the major pillars to spur cohesion. Second, European integration has to a large degree, also been associated with the reduction of barriers for a free flow of goods, labor, and capital.

This free flow of goods and production factors, however, makes it hard to predict the spatial distribution of the policy effects and to specifically target economic policy measures on the lagging regions. It is ex ante not clear how a policy affects the economic performance of neighboring regions, and how the neighboring regions' economic performance feeds back on the region at which the policy is targeted. Due to such feedbacks the overall effect might well be negative such that a policy intended to accelerate the convergence actually leads to divergence.

In our paper we analyze exactly these questions by considering short-, medium- and long-term effects of policy measures, which aim at fostering convergence, on output and real convergence in a two-region setup of an agent-based macroeconomic model (the Eurace@Unibi model). We define two policies that can be implemented in the less developed region. The first policy is a human capital policy that leads to an upgrade of the general skill level in the population. The second policy provides subsidies to those firms that invest in the most recent technological vintages. These subsidies give firms incentives to modernize their capital stock which can close the technological gap to the superior region.

The choice of these policies for our experiments is strongly motivated by the regional policies funded by the European Union. ${ }^{1}$. The ERDF aims at strengthening economic and social cohesion in the EU by correcting imbalances between its regions. In short and among other things, the ERDF finances direct aid to investments in companies (in particular small and

\footnotetext{
${ }^{1}$ See $h t t p: / / e c . e u r o p a . e u / r e g i o n a l \_p o l i c y / t h e f u n d s / i n d e x \_e n . c f m$, accessed on August 9th, 2012.
} 
medium sized enterprises) in order to create sustainable jobs. Large parts of this fund are spent to support investments in physical capital, mostly through non-repayable grants, but also other tools, such as soft loans. The ERDF also supports the build-up of infrastructures notably linked to research and innovation, telecommunications, environment, energy and transport. The ESF is set up to improve employment and job opportunities in the European Union. This fund supports actions in the member states in the areas of adapting workers and enterprises, lifelong learning schemes, designing and spreading innovative working organizations. It also targets at strengthening human capital by reforming education systems and setting up a network of teaching establishments. This short description shows that under the roof of these funds, we find mostly policies targeted at helping to build up human capital and/or technology improvements.

The available budget for the ERDF and ESF is sizeable. For the period from 2007 to 2013, 277 bn Euros are allocated which makes about 28.5\% of the total EU budged. As all the cohesion policy programs are matching funds with co-financing by the member countries, total available funding is almost 560 bn Euros which is about one quarter of the Italian and more than one half of the Spanish yearly gross domestic product.

Although there is a vivid debate about the past success of EU cohesion policy, which is based on a variety of econometric techniques (see Becker et al. (2010) for a recent contribution and a brief survey of the relevant literature), the model-supported basis for a prediction of the effect of such measures, which target either the quality of human capital or technology upgrading in a spatial framework with labor market frictions, is weak.$^{2}$ Considering the well established complementarity between workers' skills and the level of technology employed by firms (see our brief discussion in the next section) it is clear, that each of these policies, if successful, should affect the dynamics of both human and physical capital. The effective use and the adoption of different vintages of technology in a region is influenced not only by policies directly subsidizing physical investments, but also by the skill distribution in that region, which is in turn influenced both by local human capital policies

\footnotetext{
${ }^{2} \mathrm{~A}$ rare model-based contribution related to the issues raised here is Arcalean et al. (2012), where the authors study in the framework of a two region, two sector overlapping generations model the effects of the allocation of structural funds between public education and infrastructure. However, the paper differs in several respects from our main focus. First, infrastructure provides a public good increasing productivity of all firms, whereas the technology policy in this paper provides incentives for individual firms to acquire capital goods of high quality thereby improving productivity of some selected firms (those who invest). Second, a major aspect of our analysis, namely the complementarity between the dynamics of skills of workers and technology choices of firms, is not present in Arcalean et al. (2012). Also, spatial labor market frictions play no role in their analysis.
} 
and by the mobility of workers. Hence, although these cohesion policies all aim at the improvement of the productivity in the target region, they rely on quite different mechanisms and might therefore be differently affected by varying degrees of spatial labor market frictions. For this reason, a systematic comparison of the effectiveness of policies targeting human capital endowment and diffusion of technologies into weaker regions, as they are center stage in European cohesion policies, as well as the interplay of these policies with the policies fostering labor mobility between the regions, needs further investigation. More specifically we seek to answer the following policy related questions:

1. How does each of the considered cohesion policies affect output growth in both regions and convergence?

2. How are the cohesion policy effects influenced by labor mobility?

Our aim is to address these questions under consideration of the complementarity of the dynamics of skills and quality of production technology on the firm level, where this complementarity is due to learning by doing of workers and endogenous technology choice by firms. Dealing with this complementarity requires a model that captures technology choices of individual firms, where these choices are affected by firm specific characteristics like the availability of appropriate skills in the own workforce, as well as the evolution of the distribution of (specific skills) in the workforce and skill specific labor flows across regions.

We opt for a closed agent-based model with two regions as the most appropriate tool to gain insights into the emergent dynamics on the labor and goods markets. Heterogeneous firms and households interact on labor and consumption goods markets. Productivity of firms is determined by the specific skills of its workers (which are updated due to learning by doing) as well as the quality of its vintage structured capital stock. New vintages become available over time from the capital goods sector and are integrated into the active capital stock based on investment and vintage choice decisions of firms. Decision making of firms and households is modeled in a rule-based manner, where the decision rules implemented in the model have strong empirical foundations and resemble heuristics or rules of thumb that have been put forward in the specific literature streams that deal with the different decision problems arising for the agents in the model. This framework allows us to use a strongly micro-founded model for the analysis of short, medium and long run policy effects arising from heterogeneous and interacting firms and workers in a spatial context. We set up the model in a way that one region is initially endowed with a capital stock whose technological level is 
close to the frontier, while the other region's capital shows a considerable gap. The human capital differs in that the labor force in the first region is better educated and, by working with the most recent technology, has acquired higher specific skills than workers in the other region.

In order to examine the effectiveness of the policies targeted at the human capital and technologies, and to identify the importance of regional labor market frictions, on output and convergence, we run and compare two different experimental setups. The two setups, within which the human capital and technology policies are analyzed, differ with respect to the level of integration of the two local labor markets. In the first setup the labor markets are fully integrated such that there are small frictions and all workers have almost unhindered access to both local labor markets. In the other setup the labor markets are completely separated and workers can only work in their home region. These are two extremes where the former may be seen as the political aim of an integrated European labor market. Actual labor mobility across regions varies quite substantially within Europe (see e.g. European Commission (2006)), where across larger distances and language barriers labor flows are relatively small. In particular, cross country migration is still low, although it increased after the recent EU enlargement. 3 Commuting across regions is a more relevant source of labor flows with the percentage of commuters ranging from $2 \%$ to $20 \%$ for different EU countries, where, however, the largest part of the commuting takes place between regions within the same country (European Commission (2006)).

Our analysis is based on a systematic statistical analysis of batches of simulation runs under the different policies in the two considered labor market scenarios. As a methodological innovation to the literature on agent-based policy models we use penalized spline estimates to capture the evolution of policy impacts over time.

The main results of our analysis are that the human capital policy is only effective in terms of fostering cohesion if labor markets are separated. If labor markets are integrated, output actually falls in the lagging region at which the policy is targeted. Technology policies speed up convergence for integrated and separated labor markets and their effect is substantially stronger if they are specified such that they incentivize firms to purchase latest vintages. The mechanisms responsible for the strong influence of spatial labor market frictions on the policy effects are identified and discussed. Thereby this paper contributes to a better qualitative understanding of the reasons why cohesion policy measures might have no effect or even effects that run counter the

\footnotetext{
${ }^{3}$ In 2010, 2.8\% of working-age European citizens lived in another EU member state compared to $2.0 \%$ in 2004 (European Commission (2011)).
} 
intention of the policy maker. These insights have clear policy implications, which we discuss in the last section of the paper. The mechanisms we identify rely on the interplay of labor flows of low and high skilled workers with the technology choices of firms in a region and the shift of demand due to the competitiveness of firms in different regions and do not seem to be considered in the existing literature in this area. Also, the consideration of policy effects on different time scales is an innovative contribution relative to previous model based policy analyses.

In the following section we relate our contribution to the existing literature. Section 3 lays out the model. Section 4 introduces the policy experiments and discusses the results. The last Section 5 concludes.

\section{Related Literature}

Our contribution on evaluating the effects of EU policies on convergence is mainly related to three streams of literature: work on technology adoption, work on convergence and effects of cohesion policy, and work on agent-based macroeconomic modeling. We briefly discuss our contribution relative to these three streams.

Recently, based on a model of technology adoption as laid out in Comin and Hobijn (2010), Comin and Hobijn (2011) provide evidence that U.S. aid given within the Marshall plan accelerated the speed of adoption of new technologies. Recurring on a sample of 10 technologies for 39 countries for the postwar period, they find that countries which benefited from these policies reduced on average the adoption lag for new technologies by 4 years. Further important contributions studying technology adoption are Parente (1994), Parente and Prescott (1994), or Basu and Weil (1998). We differ from this work by modeling technology adoption as a process for which the availability of a skilled workforce within a particular firm is crucial.

A simple macroeconomic model, where the technology choice of firms is influenced by the local availability of skills, is developed and analyzed in Caselli and Coleman (2006). Their model provides a good explanation for the empirical observations that higher-income countries use skilled labor more efficiently, but unskilled labor less efficiently than lower-income countries. This work, however, does not consider the role of workers' endowments of skills on the firm level for the technology choices of firms and does not have a policy focus.

Similarly to our policy experiments Mateos-Planas (2001) investigates school effectiveness and distortions to the costs of technology adoption on per-capita output, educational attainment, and age of technologies. There 
is technology specific learning, and education either improves the ability of agents to learn new technologies or provides a productivity advantage. In contrast, we model the interplay of general and specific skills of workers within a firm, and incentives of firms to invest into new technologies. Workers improve their specific skills on-the-job (see, e.g., Argote and Epple, 1990) faster if they have higher general skills. Also, contrary to our contribution, the analysis by Mateos-Planas (2001) lacks the spatial dimension.

Combining empirical work with a theoretical arguments based on an endogenous growth model, Aghion et al. (2009) show that in regions, where productivity is far from the frontier, educational investments in (research oriented) universities have negative effects on local growth rates, due to the outwards-migration of high-skilled workers. Although this empirical observation is in accordance with our findings the main focus of our underlying model is quite distinct from that in Aghion et al. (2009). Contrary to our focus on the interplay of the dynamics of firm's technology choice, workers' skill adjustment and inter-regional competition, they mainly study the allocation of workers between imitative and innovative activities in a region, assuming that the elasticity of skilled labor is higher in innovation than in imitative activities. Furthermore, in their paper predictions of the effects of policies regard long-run growth rates in one region, whereas we consider as well short and medium run effects. In that sense our analysis should be seen as complementary to that in Aghion et al. (2009).

Our modeling of firms' technology choices also distinguishes this contribution from the work based on the concept of directed technological change (see, e.g. Acemoglu, 1998, Acemoglu and Zilibotti, 2001). Contrary to the majority of work in this area, where it is assumed that the intensity of R\&D leading to high quality capital goods is influenced by the (local) skill distribution of workers, our focus is on the effects of the local skill distribution on the technology choice of consumption good producers and, therefore, on the speed of diffusion of new technologies in the economy $\left.\right|^{4}$

A large literature has studied convergence between countries or between regions, mainly relying on the concept of ' $\beta$-convergence' (see, e.g., Islam, 2003 for a review). Previous empirical work on, particularly, the effectiveness of European regional policies with respect to regional convergence is mixed. Studies taking a national perspective, such as Beugelsdijk and Eijffinger (2005) find positive effects of the Structural Funds Program on GDP growth, or at least conditionally positive effects (Ederveen et al., 2006) mean-

\footnotetext{
${ }^{4}$ Empirical evidence, based on firm level data, that the intensity of a firm's innovative activities is (positively) influenced by the skill level of its employees is provided by Piva and Vivarelli (2009).
} 
ing that growth rates rise for countries with good institutions. For studies using disaggregated regional data, the findings with respect to the growth effects are inconclusive. One of the earliest attempts to evaluate the role of the Structural Funds Programme can be found in Boldrin and Canova (2001). They analyzed NUTS 2 data for 221 regions for the years 1980 to 1996, finding that disparities between regions were neither growing nor decreasing, and that EU policies have little relationship with fostering growth. Contrarily, also using sub-national data, Cappelen et al. (2003) for example, find positive growth effects. Ramajo et al. (2008) provide evidence for spatial convergence clubs in Europe, and faster conditional convergence in relative income of cohesion-fund countries, i.e. Ireland, Greece, Portugal, and Spain. Finally, Becker et al. (2010) detect positive growth effects for so-called Objective 1 transfers within the structural program but no effects on regional employment. Reasons for the differing findings may be that the data employed refers to various levels of disaggregation, and that some studies look into the overall effect of the EU funding while others evaluated more specific programs. We shall come back to this assessment in the concluding remarks when mirroring our simulation results with these empirical findings.

Finally, we contribute to the literature on agent-based macroeconomic modeling. In the last ten years a number of closed macroeconomic models using an agent-based approach have been developed (see, e.g. Gintis, 2007; Dosi et al., 2010, Delli Gatti et al., 2010; Ashraf et al., 2011; Dawid et al. 2012a; Raberto et al., 2012; Wolf et al., 2012). Several of these agentbased macroeconomic models have shown the importance of the approach for economic policy design. For example, the effect of labor market integration policies on the convergence of regions has been analyzed by Dawid et al. (2012a). Dosi et al. (2010) have looked into the (long run) effects of policies aiming at the strengthening of demand and of policies facilitating the speed of technological change as well the interaction of these polices. Monetary policies are addressed in Ashraf et al. (2012) or Arifovic et al. (2012), whereas regulatory issues relating to credit and financial markets have been analyzed by Delli Gatti et al. (2010) or Ashraf et al. (2011) within agent-based macroeconomic models. We differ from the existing agent-based macroeconomic models as our set-up jointly features a spatial dimension and technology adoption by firms which is complementary to an evolving stock of specific skills within a firm. 


\section{The Model}

\subsection{Overall Structure}

The Eurace@Unibi model describes an economy containing labor, consumption goods, capital goods, financial and credit markets in a regional context. The economy is inhabited by numerous instances of different types of agents: firms (consumption goods producers and capital goods producers), households and banks. Each of these agents is located in one of the regions. Additionally, there is a single central bank and a government that collects taxes and finances social benefits as well as potentially some economic policy measures, where policies might differ between regions. Finally, there is a statistical office (Eurostat) that collects data from all individual agents in the economy and generates aggregate indicators according to standard procedures. These indicators are distributed to the agents in the economy (which might use them e.g. as input for their decision rules) and also stored in order to facilitate the analysis of the simulation results. Due to space constraint we will in this section only describe the main aspects of the model, which are crucial for the understanding of the results discussed below. A detailed description of the entire model is provided in Dawid et al. (2012b).

Capital goods of different quality are provided by capital goods producers with infinite supply. The technological frontier (i.e. the quality of the best currently available capital good) improves over time, where technological change is driven by a stochastic (innovation) process. Firms in the consumption goods sector use capital goods combined with labor input to produce consumption goods. The labor market is populated with workers that have a finite number of general skill levels and acquire specific skills on the job, which they need to fully exploit the technological advantages of the capital employed in the production process. Every time when consumption goods producers invest in new capital goods they decide which quality of capital goods to select, thereby determining the speed by which new technologies spread in the economy. Consumption goods are sold at local market platforms (called malls), where firms store and offer their products and consumers come to buy goods at posted prices. Labor market interaction is described by a simple multi-round search-and-matching procedure where firms post vacancies, searching workers apply, firms make offers and workers accept/reject. Wages of workers are determined, on the one hand, by the expectation the employer has at the time of hiring about the level of specific skills of the worker, and, on the other hand, by a base wage variable, which is influenced by the (past) tightness of the labor market and determines the overall level of wages paid by a particular employer. Banks collect deposits from households 
and firms and give credits to firms. The interest that firms have to pay on the amount of their loan depends on the financial situation of the firm, and the amount of the loan might be restricted by the bank's liquidity and risk exposure. There is a financial market where shares of single asset are traded, namely an index bond containing all firms in the economy. The dividend paid by each share at a certain point in time is determined by the sum of the dividends currently paid by all firms. The central bank provides standing facilities for the banks at a given base rate, pays interest on banks' overnight deposits and might provide fiat money to the government.

Firms that are not able to pay the financial commitments declare illiquidity. Furthermore, if at the end of the production cycle the firm has negative net worth, the firm is insolvent and insolvency bankruptcy is declared. In both cases it goes out of business, stops all productive activities and all employees loose their jobs. The firm writes off a fraction of its debt with all banks with which it has a loan and stays idle for a certain period before it becomes active again.

The spatial extensions of the markets differ. The capital goods market is global meaning that firms in all regions buy from the same global capital good producer and therefore have access to the same technologies. On the consumption goods market demand is determined locally in the sense that all consumers buy at the local mall located in their region, but supply is global because every firm might sell its products in all regional markets of the economy. Labor markets are characterized by spatial frictions determined by commuting costs that arise if workers accept jobs outside their own region. It is assumed that firms have access to all banks in the economy and, therefore, credit markets operate globally.

The choice of the decision rules in the Eurace@Unibi model is based on a systematic attempt to incorporate rules that resemble empirically observable behavior documented in the relevant literature. Concerning households, this means that for example empirically identified saving rules are used and purchasing choices are described using models from the Marketing literature with strong empirical support. With respect to firm behavior we follow the 'Management Science Approach', which aims at implementing relatively simple decision rules that match standard procedures of real world firms as described in the corresponding management literature. A more extensive discussion of the Management Science approach can be found in Dawid and Harting (2012).

Agent actions can be time-driven or event-based, where the former can follow either subjective or objective time schedules. Furthermore, the economic activities take place on a hierarchy of time-scales: yearly, monthly, weekly and daily activities all take place following calendar-time or subjective agent- 
time. Agents are activated asynchronously according to their subjective time schedules that is anchored on an individual activation day. These activation days are uniformly randomly distributed among the agents at the start of the simulation, but may change endogenously (e.g., when a household gets re-employed, its subjective month gets synchronized with the activation day of its employer due to wage payments). This modeling approach is supposed to capture the decentralized and typically asynchronous nature of decision making processes and activities of economic agents.

\subsection{Agents, Markets, and Decisions}

\subsubsection{Output Decision and Production}

Consumption goods producers need physical capital and labor for production. A firm $i$ has a capital stock $K_{i, t}$ that is composed of different vintages $v$ with $v=1, \ldots, V_{t}$, where $V_{t}$ denotes the number of available vintages a time $t$. The accumulation of physical capital by a consumption goods producer follows

$$
K_{i, t+1}^{v}=(1-\delta) K_{i, t}^{v}+I_{i, t}^{v}
$$

where $\delta$ is the depreciation rate and $I_{i, t}^{v} \geq 0$ is the gross investment in vintage $v$.

The production technology in the consumption goods sector is represented by a Leontief type production function with complementarities between the qualities of the different vintages of the investment good and the specific skill level of employees for using these vintages. Vintages are deployed for production in descending order by using the best vintage first. For each vintage the effective productivity is determined by the minimum of its productivity and the average level of relevant specific skills of the workers. Accordingly, output for a consumption goods producer is given by

$$
Q_{i, t}=\sum_{v=1}^{V_{t}} \min \left[K_{i, t}^{v}, \max \left[0, L_{i, t}-\sum_{k=v+1}^{V_{t}} K_{i, t}^{k}\right]\right] \cdot \min \left[A^{v}, B_{i, t}\right],
$$

where $A^{v}$ is the productivity of vintage $v$ and $B_{i, t}$ denotes the average specific skill level in firms as explained in more detail in Section 3.2.3. The fact that the considered production function takes into account the vintage structure of the capital stock and that firms select among different available vintages enables us to capture the effect of workers' skills on the incentives of firms to invest into new technologies (see Section 3.2.4).

Once every month each firm determines the quantities to be produced and delivered to each regional mall the firm is serving. Actual demand for 
the product of a firm in a given mall and a given month is stochastic (see below) and there are stock-out costs, because consumers intending to buy the product of a firm move on to buy from a different producer in case the firm's stock at the mall is empty. Therefore, the firm faces a production planning problem with stochastic demand and stock-out cost. The simplest standard heuristic used in the corresponding Operations Management literature prescribes to generate an estimation of the distribution of demand and then choose the planned stock level after delivery such that the (estimated) stockout probability during the following month equals a given parameter value (which is influenced by stock-out costs, inventory costs and risk attitude of the firm (see e.g. Silver et al. (1998)). Firms in the Eurace@Unibi model follow this simple heuristic, thereby generating a target production quantity for the considered month. Based on the target production quantity the firm determines the desired input quantities of physical capital and labor. Realizing this production plan might induce the need to buy new physical capital, hire new labor or to obtain additional credit. Although there is infinite supply of physical capital the firm might be rationed on the labor and credit market. In this case the firm accordingly adjusts its production quantity downwards.

\subsubsection{Pricing Decision}

Consumption goods producers set the price of their products once a year which is consistent with empirical observations (see, e.g., Fabiani et al., 2006). The pricing rule is inspired by the price setting described in Nagle and Hogan (2006, ch.7), a standard volume on strategic pricing in the Managerial literature. Firms seek for a profit-maximizing price taking into account the trade-off between price, sales and costs.

To obtain an indication of the effect of price changes on sales the consumption goods producers carry out simulated purchase surveys (see Nagle and Hogan, 2006, pp. 300). A representative sample of households is asked to compare a firm's product with the set of the currently available rival products for a range of prices. Households' answers are based on the same decision rules they use for their real purchasing decisions. Based on the resulting demand estimations and cost considerations firms choose the price which maximizes their expected discounted profit stream over their planing horizons.

\subsubsection{Adjustment of Specific Skills of Workers}

Each worker $h$ has two dimensions of human capital endowments namely an exogenously given general skill level $b_{h}^{\text {gen }}$ and an endogenously increasing 
specific skill level $b_{h, t}$. General skills can be interpreted as formal qualification or general embodied abilities while specific skills are experiences or abilities obtained on-the-job reflecting the productivity of each worker. For simplicity it is assumed that only two general skill levels exist $b^{\text {gen }} \in\{1,2\}$, where $b^{\text {gen }}$ refers to the general skill level. General skills are observable by firms in the hiring process while specific skills are not. They become observable during the production process. Acquisition of specific skills in the production is faster for the higher general skills. Formally, the workers increase the specific skills over time during production by a learning process. The speed of learning depends on the general skill level $b_{h}^{\text {gen }}$ of the worker $h$ and the average quality of the technology $A_{i, t}$ used by employer $i$ :

$$
b_{h, t+1}=b_{h, t}+\chi\left(b_{h}^{g e n}\right) \cdot \max \left[0, A_{i, t}-b_{h, t}\right] .
$$

Here $b_{h, t}$ are the specific skills of worker $h$ in period $t$ and $\chi\left(b_{h}^{\text {gen }}\right)$ increases with general skills $b_{h}^{\text {gen }}$ and $0<\chi\left(b_{h}^{\text {gen }}\right)<1$. The distribution of general skills in a region is deliberately kept exogenous in the model, since the effect of changes in this distribution is one of the key policy experiments in our analysis. Endogenizing the general skill distribution in a region would require an explicit representation of educational choices and the inclusion of an education sector, which would make the model much more complex and is beyond the scope of this paper.

\subsubsection{Technological Change}

The supply of the capital goods and the process of technological change is modeled in a very simplified stylized way, since the focus of our analysis lies on the interaction of the dynamics on the labor and consumption goods markets. There is a monopolistic capital goods firm that offers different vintages of the capital good $v=1, \ldots, V_{t}$, which differ regarding their productivity $A^{v}$, at infinite supply. This firm is therefore able to satisfy all emerging capital demand of consumption goods firms. Furthermore, the capital good is produced without input factor requirements and, in order to close the model, all revenues are channeled back into the economy by distributing them to households in the form of dividends. New vintages become available over time following a stochastic process. To avoid spurious growth effects, due to stochastic differences in the dynamic of the technological frontier between runs, we use in all considered runs the identical realization of the stochastic process governing the emergence of new vintages.

The pricing of the vintages is modeled as a combination of cost-based and value-based pricing, where the growth rate in the first term follows the growth rate of average labor costs and the value-based price component estimates 
the value that each vintage has for a reference firm whose workforce consists of the economy wide average levels for the specific skills as well as general skills.

\subsubsection{Investment and Vintage Choice}

If consumption good producers have a target output level which cannot be produced with their current capital stock, they acquire new capital. To this end, a consumption goods firm has to choose from the set of available vintages. For the decision in which vintage to invest the complementarity between specific skills and technology plays an important role: due to the inertia of the specific skill adaptation, the effective productivity of a vintage with $A^{v}>B_{i, t}$ is initially below its quality. It converges to $A^{v}$ over time as the specific skills of workers at the firm catch-up to the quality of the vintage. Therefore, the firm computes a discounted sum of estimated effective productivities over a fixed time horizon $S$. The specific skill evolution is estimated for each time step within $[t, t+S]$ using (3), where the firm inserts its average general and specific skill values. A logit choice model based on the ratio of the estimated effective productivity and price for each available vintage determines which vintage is ordered. In several parts of the Eurace@Unibi model choices of decision makers are described by logit models. These models are well suited to capture decisions where individuals try to maximize some objective function which depends on some variables common to all decision makers and are explicitly represented in the model, as well as on aspects that are idiosyncratic to each decision maker and captured in the model by a stochastic term.

\subsubsection{Labor Market Interaction}

If the current workforce of a firm is not sufficient to produce its target output, the firm posts vacancies for production workers. The wage it offers has two constituent parts. The first part is the market driven base wage $w_{i, t}^{\text {base }}$. The base wage is paid per unit of specific skill. If the firm cannot fill its vacancies and the number of unfilled vacancies exceeds some threshold $\bar{v}>0$ the firm raises the base wage offer by a fraction $\varphi$ to attract more workers, i.e.

$$
w_{i, t+1}^{\text {base }}=(1+\varphi) w_{i, t}^{\text {base }} .
$$

The second part is related to the specific skills. Since the specific skills represent the (maximal) productivity of the employees the wage $w_{i, t}$ is higher for higher specific skills. For each of the general-skill groups the firm $i$ offers 
different wages $w_{i, t, g}^{O}$ in period $t$. The wage offers are given by

$$
w_{i, t, g}^{O}=w_{i, t}^{\text {base }} \times \min \left[A_{i, t} \bar{B}_{i, t-1, g}\right]
$$

where $\bar{B}_{i, t-1, g}$ are the average specific skills of all employees with general skill $g$ in the firm. The underlying assumption of this determination of wage offers is that firms can observe general but not specific skills of job applicants. Therefore they use the average specific skills of all employees with general skill $g$ in the firm in order to estimate the specific skills of an applicant with general skill level $g$. This wage setting rule is a reduced form representation of the outcome of firm-level wage negotiations taking into account workers' expected productivity in the firm as well as workers' outside option.

An unemployed worker takes the wage offers posted by searching firms into consideration and compares them with his reservation wage $w_{h, t}^{R}$. An unemployed worker will only apply at a firm that makes a wage offer such that

$$
(1-c) w_{i, t, g}^{O}>w_{h, t}^{R},
$$

where $w_{h, t}^{R}$ denotes the reservation wage of the worker and $c \in[0,1]$ captures the commuting costs. If workers and employers are in the same region we have $c=0$. For simplicity it is assumed that workers commute to an employer outside their own region rather than moving to that region, which means in particular that the worker consumes in his home region 5

The level of the reservation wage is determined by the current wage if the worker is employed, and in case of an unemployed worker by his previous wage, where the reservation wage declines with the duration of unemployment. The reservation wage never falls below the level of unemployment benefits. If the unemployed worker receives one or more job offers he accepts the job offer with the highest wage offer. In case he does not receive any job offers he remains unemployed.

In case the workforce of a firm is too large relative to its target output level, the firm adjusts its number of workers, where employees with low general skills are dismissed first. Additionally, there is a small probability for each worker-employee match to be separated in each period. This should capture job separations due to reasons not explicitly modeled.

\footnotetext{
${ }^{5}$ Empirical evidence shows that even if workers move to the region of their employer a considerable part of their wage income is consumed in their home region due to remittances sent back. This holds in particular for workers from low productivity countries which recently joined the EU (see European Commission (2011)).
} 


\subsubsection{Consumption Market Interaction}

The consumption goods market is modeled as a decentralized goods market. Each local market is represented by a mall at which the consumption goods producers can offer and sell their products to their customers. While firms are free to serve all malls regardless their spatial proximity, households always choose the mall which is located in their region.

Households go shopping once a week and try to spend their entire weekly consumption budget for one good. The consumption budget is determined using a (piecewise) linear consumption rule according to the buffer-stock approach (see Carroll (1997) and Allen and Carroll (2001)). At the beginning of their shopping procedure they get information about the prices of all available goods at the mall, but they get no information about the available quantities. The decision which good to buy is described using a logit-choice model with strong empirical foundation in the Marketing literature (see e.g. Malhotra (1984)). An important parameter in this respect is the coefficient of the price of a good in the logit choice function. This parameter, denoted as $\gamma^{C}$, governs the price sensitivity of consumers and therefore the intensity of competition between the consumption good producers. Qualitative features of the economic dynamics are substantially influenced by changes in this parameter and therefore we will check the robustness of our qualitative findings for variations of this parameter.

Households have asynchronized shopping days and thus on each day of the months there is in general some shopping activity in each mall. The consumption requests for the different goods are collected by the mall and, if the total demand for one good exceeds its mall inventory level then the mall has to ration the demand. In this case the mall sets a rationing quota corresponding to the percentage of the total demand that can be satisfied with the available goods. Each household receives then the indicated percentage of the requested consumption good.

After the shopping activity rationed households may still have left over budget. Those households have the opportunity to spend the remaining budget for another good in a second shopping loop. In this case the shopping process is repeated as described above.

The production of the consumption goods firm follows a fixed time schedule with fixed production and delivery dates. Even if the mall stock is completely sold out it can only be refilled at the fixed delivery date. Consequently, all the demand that exceeds the expected value of the monthly sales plus the additional buffer cannot be satisfied. 


\subsection{Parametrization and Validation}

In order to determine the values and ranges of parameters to be used in the policy experiments we follow an approach that combines direct estimation of parameters for which empirical observations are available with an indirect calibration approach in order to establish confidence in the ability of the model to capture economic mechanisms which are relevant for real world economic dynamics. Standard constellations have been identified, where values of parameters are chosen to reflect empirical evidence whenever possible and where a large set of stylized facts can be reproduced. Furthermore, the fact that the development of the Eurace@Unibi model follows as far as possible the Management Science approach, briefly discussed above, provides empirical grounding to individual decision rules, thereby addressing the important point of empirical micro-foundations for modeled behavior. The set of macroeconomic stylized facts that have been reproduced by the standard constellations of the Eurace@Unibi model includes persistent growth, low positive inflation and a number of important business cycle properties: persistent fluctuations of output; pro-cyclical movement of employment, consumption and investment, where relative sizes of amplitudes qualitatively match those reported e.g. in Stock and Watson (1999), counter-cyclical movement of wages and firm mark-ups. On the industry level the model generates persistent heterogeneity in firm-size, profit rates, productivity and prices in accordance with empirical observations reported e.g. in Dosi et al. (1997). Also labor market regularities, like the Beveridge curve, are reproduced by the model with benchmark parameter constellations. The reader is referred to Dawid et al. (2012b) for a more detailed discussion of this issue. Tables with the list of parameter values used in the simulations underlying this paper are provided in the Online-Appendix.

\section{Policy Analysis}

\subsection{General Setup, Method of Policy Evaluation, Con- sidered Policies}

Our policy experiments are concerned with the convergence between a high tech and a low tech region in a two-region version of the model described above. Table 1 summarizes the initializations of the key variable for the two distinct regions $\mathrm{R} 1$ and $\mathrm{R} 2$. At time $t=0$ the quality of the capital stock in the high tech region $\mathrm{R} 1$ is set to 1.5 , and to 1.0 in the low tech region. The choice of the (adapting) specific skills corresponds initially to the quality of 
Table 1: Initialization of capital stock and skills

\begin{tabular}{l|cc}
\hline & Region 1 (R1): high tech & Region 2 (R2): low tech \\
\hline Initial quality of capital stock & 1.5 & 1.0 \\
Initial specific skills & 1.5 & 1.0 \\
General skill distribution & $0.8 / 0.2$ & $0.2 / 0.8$ \\
\hline
\end{tabular}

the capital stock. In R1 $80 \%$ of the workers have high general skills, and the remaining part has low general skills. For R2 the general skill distribution is inverted. The technological frontier at $t=0$ is set to a quality of 1.7 and afterwards grows at an annual rate of 1.8 percent. Firms in both regions may purchase an investment good of that quality, i.e. investment goods markets are integrated from the beginning of the simulation. The same holds for the consumption goods markets.

Within this setup we mimic the European Union integration policies by introducing a subsidy scheme that influences firms' investment incentives, and by altering the general skill distributions in the two regions. More specifically, we are running two policy experiments:

1. In what we are going to call the Human Capital Policy (HC) the general skill level of R2 is upgraded to the general skill level of R1.

2. In what we are going to call Technology Policy (Tech) firms' investments in $\mathrm{R} 2$ are subsidized if equipment is bought from the technological frontier.

A more detailed description of the two policies is given below. Both the HC-policy and the Tech-policy are applied to two scenarios. In one scenario labor markets in the two regions are fully integrated. This means that workers face only small commuting costs $(c=0.05)$. In the second scenario, labor markets are separated implying that working in the region other than the own residence region causes prohibitively high commuting costs $(c=1)$.

In each of the two scenarios $(c=0.05$ and $c=1)$ we consider three treatments in addition to the base scenario: only HC-policy, only Tech-policy and both policies. For each of the four cases 15 runs are conducted, with each run encompassing 750 months. The time series are pooled and the policy effects are estimated using penalized spline methods (see, e.g., Kauermann et al. 2009). More technically, the isolated effects and the interacted effects of the policies are evaluated with

$$
\begin{gathered}
Y_{t, p, i}=s(t)+I_{[p(H C)=1]} s_{H C}(t)+I_{[p(\text { Tech })=1]} s_{\text {Tech }}(t)+I_{[p(H C)=p(\text { Tech })=1]} s_{\text {Int }}(t) \\
+\eta_{i}^{0}+\eta_{i}^{1} t+\varepsilon_{t, p, i},
\end{gathered}
$$


where $Y_{t, p, i}$ is the outcome variable at iteration $t$, for policy $p$, and run $i$. The baseline spline is $s(t)$ to which the policy splines are added with dummy variables $I$ indicating if the policy is turned on or off. The linear term involving $\eta_{i}^{0}$ and $\eta_{i}^{1}$ captures run-specific random effects and $\varepsilon_{t, p, i}$ is the error term. The standard deviation of the spline estimates will also be plotted in the figures in order to illustrate significance of the different policy effects over time 6

\subsection{Baseline Simulation With No Policies}

With no policy treatment we get output trajectories as shown in Figure 1 . The left panel refers to an integrated labor market and the right hand panel to a separated labor market with high commuting costs. In both scenarios the initial output levels are equal. As time elapses, however, completely different growth patterns emerge. For the high tech region R1 (black line) output grows constantly and almost quadruples until the end of the simulation period. The low tech region R2 (red line) experiences a drop in output and eventually recovers showing relatively low output growth. Overall, there is strong divergence of regional output levels. With separated labor markets, output increases in both regions but output growth is stronger in the high tech region, again leading to diverging output levels, although less extreme than in the integrated labor market scenario. Toward the end of the simulation output is lower in region 1 and higher in region 2 for closed labor markets as compared to integrated labor markets. Looking step by step into the evolution of the technologies, prices, and labor flow patterns will reveal the economic mechanism behind the results for the baseline simulation with no policies.

Figure 2 plots the trajectories for the exogenously evolving technological frontier, and the average technology used by firms for the two regions. Again, the left panel refers to an integrated labor market and the right panel to separated labor markets. For integrated labor markets, the gap between the technological frontier and average technology employed by firms for region 1 (black line) increases over time. As the gap stays approximately constant for region 2, average quality of technology employed in region 2 approaches

\footnotetext{
${ }^{6}$ All figures are based on estimations using the $\mathrm{R}$ function $\operatorname{gamm}($ ) from the package mgcv (see e.g. Wood (2011)). Although residuals in our estimation show some autocorrelation we abstain from estimating a computationally much more intensive and less stable model with $\mathrm{AR}(\mathrm{p})$ structure of the noise terms. Krivobokova and Kauermann (2007) have shown that the spline estimations are robust with respect to misspecified correlation structures, and therefore no qualitative changes of our results should be expected even if a model with more elaborated correlation structure would be used.
} 


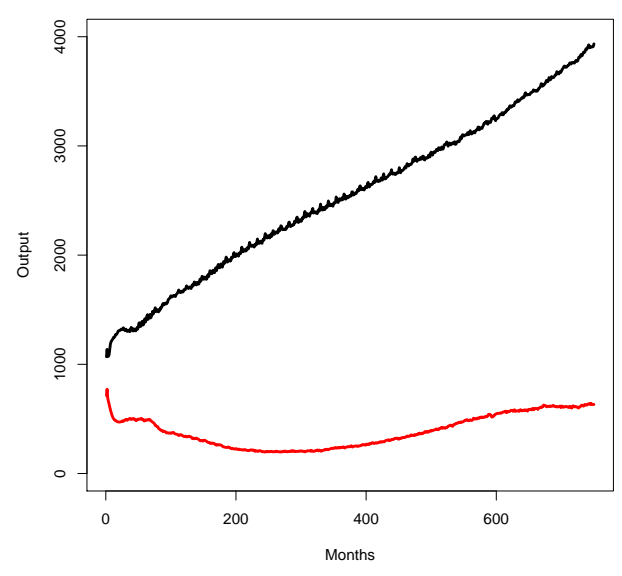

(a)

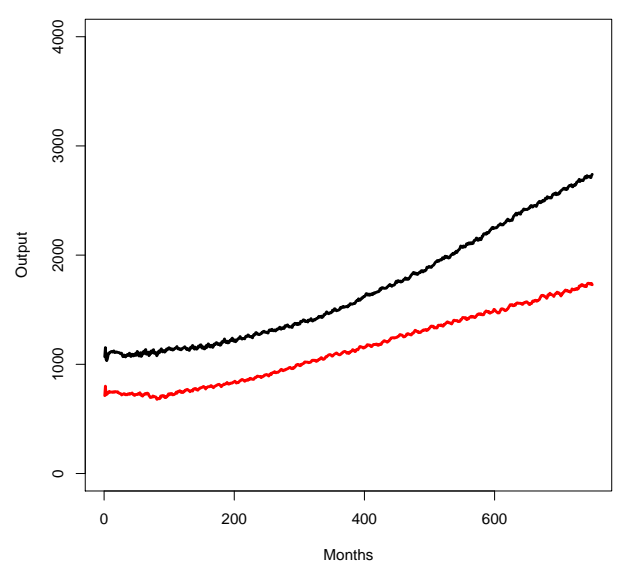

(b)

Figure 1: The evolution of output (a) integrated labor markets, (b) separated labor markets (black line: R1; red line R2)

that in region 1. For separated labor markets, region 1 stays closer to the technological frontier than with integrated labor markets. Moreover, region 2's technology gap to the frontier is increasing so that in this scenario the technological advantage of the firms in region 1 increases over time. Average technology actually used is closely related to the evolution of the output levels shown before. The catch-up of average quality of technology employed in region 2 in the scenario of integrated labor markets is a consequence of two factors, which are both driven by the strong (initial) reduction in output produced in region 2. First, as can be seen by considering the dynamics of the distribution of firm output in a region (not reported here), the downturn in region 2 has a strong selection effect in that region. Only a few firms survive, namely those that due to early high vintage choices have the best capital stocks, and they produce only small quantities. Second, given the low total output in region 2, the few surviving firms only use the qualitatively more advanced vintages. Whereas firms in region 1, given relatively high output, make also use of the older vintages, which reduces the average quality of technology.

Output patterns can be traced down to relative demand for products produced in region 1 and 2 . These relative demands are a function of the relative prices that firms from region 1 and 2 charge. As Figure 3 reveals, prices of products from region 2 are higher than those from firms in region 1 for the open labor market scenario, which explains the strongly diverging 


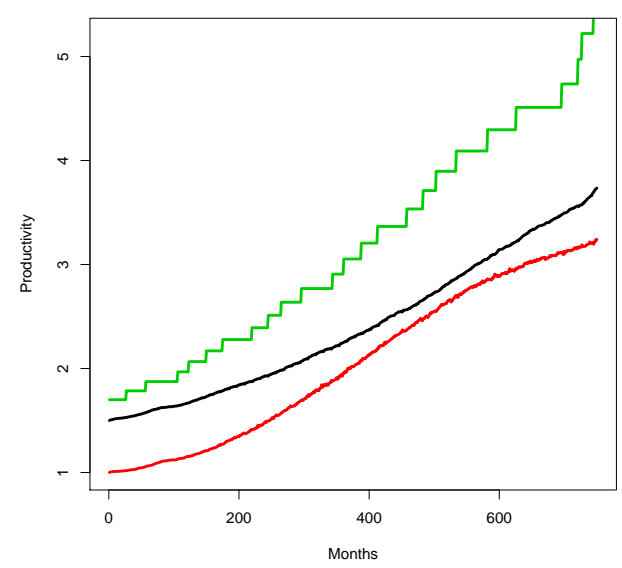

(a)

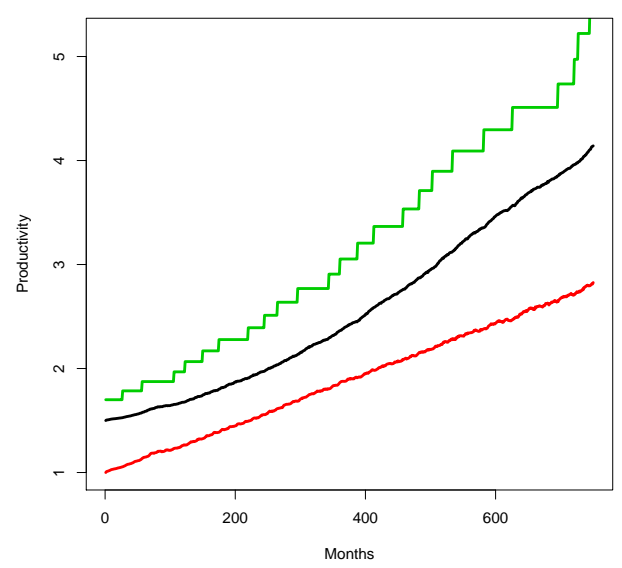

(b)

Figure 2: The evolution of technologies (a) integrated labor markets, (b) separated labor markets (green line: technological frontier; black line: average technology used in R1; red line: average technology used in R2)

output patterns. With labor costs making up a considerably large share of production costs, and prices being set as a mark-up on unit costs, we can relate the price pattern to the labor flows which arise as regional labor markets are opened. Figure 4 plots numbers of workers with low general skills (left panel) and high general skills (right panel) for integrated labor markets. One sees, that there is a significant drop in the number of workers, both high skill and low skill, in region 2. Early on firms in region 2 have to increase their base wage offer in order to attract workers in spite of the lower productivity implied by the lower quality of their capital stock. This increases their unit costs and further deepens their competitive disadvantage. However, starting approximately at month 150, the few firms in region 2 have reached a wage level that enables them to attract more and more high general skill workers. This reinforces their incentives to invest in high vintages and they are able to close the gap to region 1 with respect to the quality of their capital stock. Eventually, at about period 400 the need for additional base wage increases vanishes for firms in region 2 due to the positive evolution of the productivity and the diverging pattern between the regions with respect to prices stops. Output produced and sold by the firms in region 2 starts increasing and the growth of the output gap between the regions becomes smaller (see Figure 1 (a)). The return movement of low skilled workers induced by this expansion in region 2 however then negatively affects the 


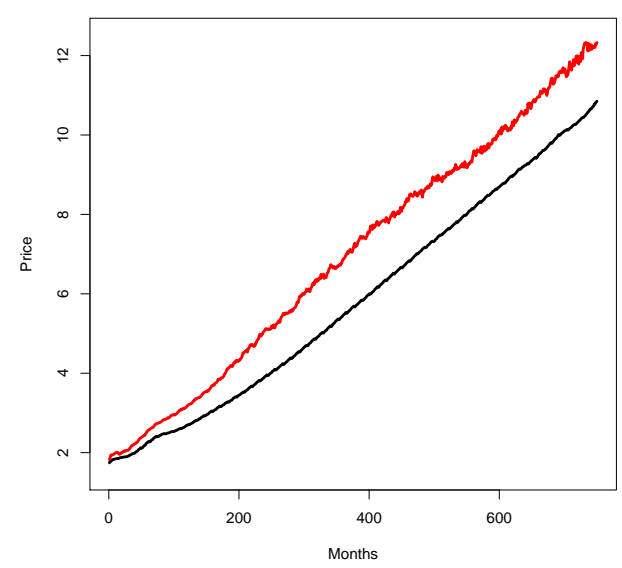

(a)

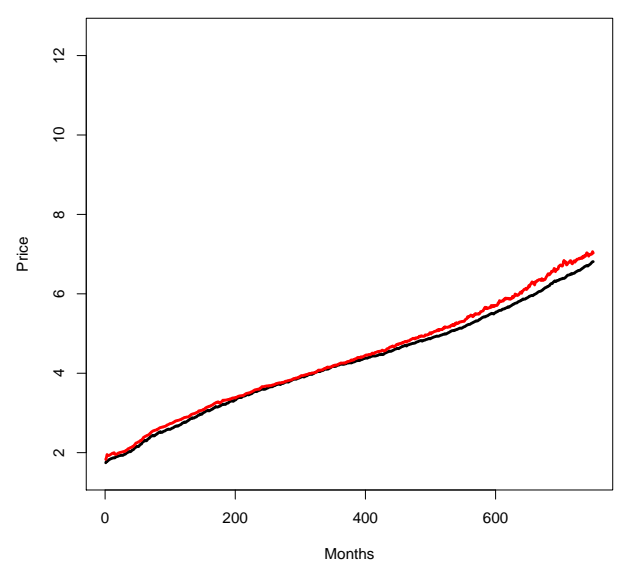

(b)

Figure 3: The evolution of mean prices (a) integrated labor markets, (b) separated labor markets (black line: R1; red line R2)

skill mix in region 2, which reduces incentives for firms to invest in new technologies. This stops the technological catch-up process by region 2 and the output gap increases again.

As can be seen in panel (b) of Figure 3, for separated labor markets the productivity advantage of firms in region 1 does not translate to a competitive advantage for this region. In this scenario wages in region 2 stay below the level in region 1 such that unit costs in both regions are approximately equal. The observation that nevertheless total output produced in region 1 is higher than that produced in region 2 can be explained by the larger production capacity of firms in region 1 . The initial advantage of region 1 in this respect is never eliminated in the absence of a price advantage of either of the two regions. The costs for firms in region 2 associated with an expansion of their capacity would be so high such that an induced competitive disadvantage would result for these firms. Due to the pricing and production planing rules of the firms they realize this and abstain from expansion such that the initial capacity advantage for region 1 (which stems from the larger productivity of capital in that region) is cemented.

Overall, the baseline simulations show that in the absence of any cohesion policy measures region 2 does not catch-up to region 1 either with respect to output or to technology in both considered labor market scenarios. 


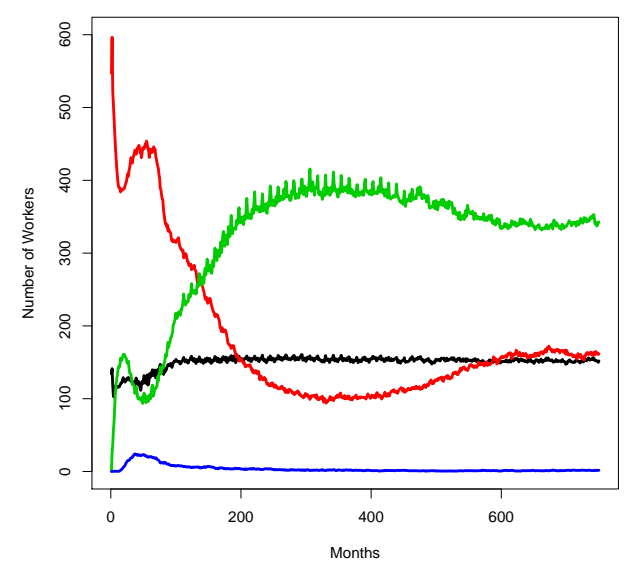

(a)

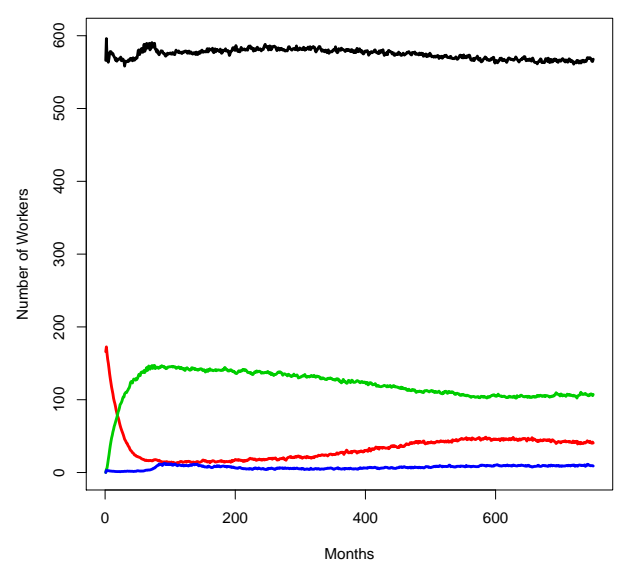

(b)

Figure 4: Commuters for integrated labor markets (a) low general skill, (b) high general skill (black line: workers from $\mathrm{R} 1$ working in $\mathrm{R} 1$; red line: workers from $\mathrm{R} 2$ working in $\mathrm{R} 2$; blue line: workers from $\mathrm{R} 1$ commuting to $\mathrm{R} 2$; green line: workers from $\mathrm{R} 2$ commuting to $\mathrm{R} 1$ ).

\subsection{Effect of Human Capital Policy}

First we examine the dynamic effects of the human capital policy. We assume that the policy is implemented at the point in time where the two regions enter their economic union $(t=0)$, but, since the build-up of human capital takes time, the effects of the policy become apparent only after a delay of ten years. At $t=120$ the distribution of general skills in region 2 becomes identical to that of region 1.7 Clearly the assumption that the gap in general skills can be completely closed by the human capital policy within ten years is very strong, but since we are mainly interested in understanding the qualitative differences in the policy effects in different economic environments, an exact quantification of the policy strength is of minor concern to us.

Figure 5 shows the effect of the HC-policy output in both regions for integrated and separated labor markets as estimated by the penalized spline model discussed above (i.e. we show the estimated splines $s_{H C}(t)$ in both scenarios). The policy effect is strikingly different, depending on whether the labor market is integrated or not. With an integrated labor market the

\footnotetext{
${ }^{7}$ For reasons of simplicity it is assumed that all individuals upgrade their skill exactly at $t=120$. A more gradual skill upgrading over time would be more realistic, but would not qualitatively alter the effects we identify. The set of individuals who upgrade their skill is selected randomly.
} 


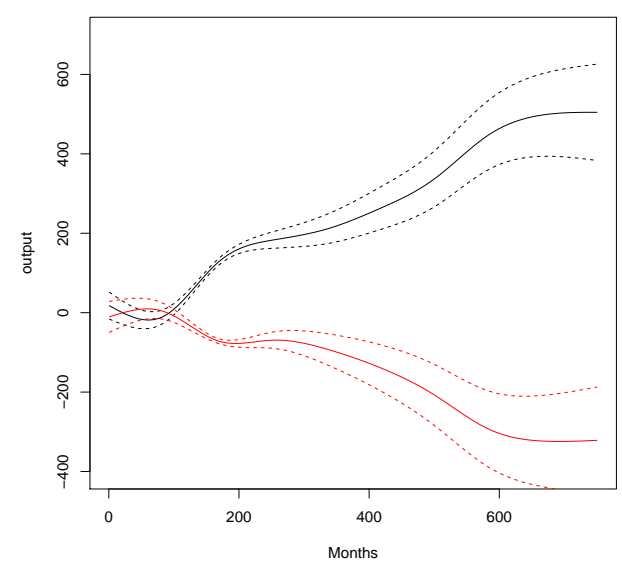

(a)

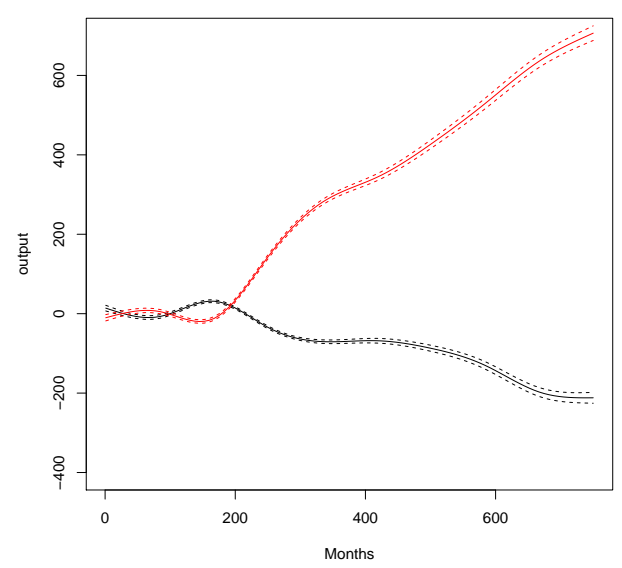

(b)

Figure 5: The effect of the human capital policy on output for (a) integrated labor markets, (b) separated labor markets (black line: R1, red line: R2).

effect on output in the target region 2 is negative, whereas output in region 1 is positively affected. These effects are not transitory, rather they seem to become more substantial as time evolves. A very different picture emerges in the scenario with separated labor markets. In this case the policy has no significant effect for an initial time interval $(t=120$ to approximately $t=200$ ), but afterward leads to an increase in the output produced in region 2, whereas the output in region 1 is negatively affected. Aggregating over both regions it can be observed that the effect of the HC-policy on total output in both regions is positive, and that the effect is much stronger if labor markets are separated. Hence, spatial frictions, preventing the free allocation of workers across regions, positively affect the overall effects of this policy.

The negative output effect of the HC-policy in region 2 arises from two countervailing forces. As intended by the HC-policy improving the workers general skills has a positive effect on firms productivity through the vintage choice. Firms in region 2 become more productive due to easier access to workers with high general skills. Figure 6 depicts the estimated effect of the HC-policy on the ratio of average vintage choice and general skills, respectively, between firms in region 2 and region 1.8 The two lines (plus standard deviation bands) in each panel describe the effects of the policy in the sce-

\footnotetext{
${ }^{8}$ Technically speaking equation $\sqrt{77}$ is estimated for $Y_{t, p, i}=\frac{\bar{v} c_{t, p, i}^{2}}{\bar{v} c_{t, p, i}^{1}}$, where $\bar{v} c_{t, p, i}^{r}$ denotes the average vintage choice at time $t$ of all firms in region $r$ in run $i$ under policy $p$.
} 
nario with integrated and separated labor markets, respectively. A positive sign of the estimated effect means that due to the HC policy the average value of the considered variable in region 2 has increased relative to region 1. Panel (a) of this figure shows that the average vintage choice of firms in region 2 increases relative to the the choice of firms in region 1 as a response to the HC-policy. The policy effect is, furthermore, larger for separated than for integrated labor markets. However, the policy sparks another indirect mechanism that overcompensates the positive effect on vintage choices so that the overall effect on investment becomes negative. Let us turn to this more involved second effect now.

As the policymakers improve general skills in region 2, the relative endowment of region 2 with high general skills improves. This is less so if labor markets are integrated, see Figure 6 (panel (b)), because high skilled workers from region 2 get job offers from firms in region 1 that net of commuting costs improve their earnings. High skilled workers from region 2 therefore eventually work in region 1 . As a result, firms in region 2 have problems filling their vacancies. They start making higher wage offers. Figure 7 (panel (a)) shows that wage offers of firms in region 2 relative to wage offers of firms in region 1 increase as a response to the HC-policy for integrated labor markets. It decreases for separated labor markets as the HC-policy increased the supply of high skilled workers in region 2 relative to region 1. As labor costs constitute a considerable share of firms' production costs, unit costs for firms in region 2 relative to region 1 increase for integrated labor markets, and decrease for separated labor markets, see panel (b) of Figure 7. The unfortunate effect on relative unit costs for region 2 with integrated labor markets ceases around period 500. However, firms in region 2 react to the alignment of costs between the two regions by an increase in mark-ups rather than by a decrease in price (see panel (d) of Figure 7). The reason for this is that firms in region 2 anticipate that the expansion corresponding to substantial own price decreases would be associated with considerable investments (which are not needed by the firms in region 1, which already have larger production capacities) and hence maximization of their estimated discounted profit streams yields substantial increases in mark-ups when their costs converge toward those of firms in region 1. Overall, region 2 suffers from a loss of competitiveness as a result of the improvement of the skills of its labor force when labor markets are integrated. Charging higher prices than firms in the competing region 1, firms in region 2 are losing demand. As lower output is produced also investments and the diffusion of new vintages decrease so that the overall effect on the productivity weighted capital stock ${ }^{9}$ is negative

\footnotetext{
${ }^{9}$ The productivity weighted capital stock is a measure that captures the size and the
} 


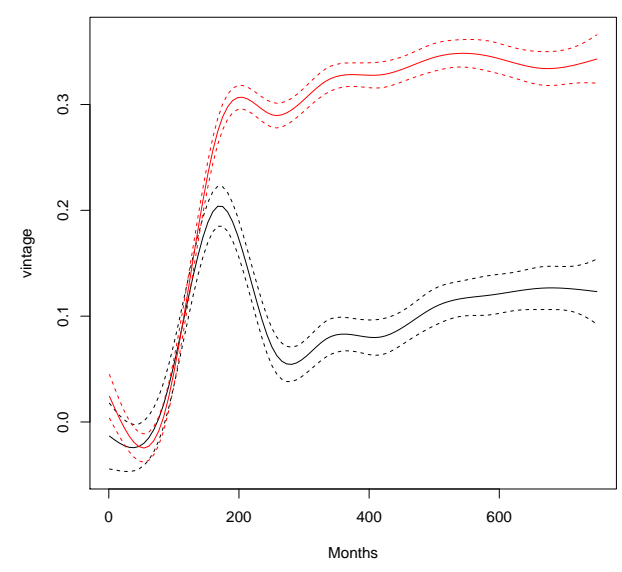

(a)

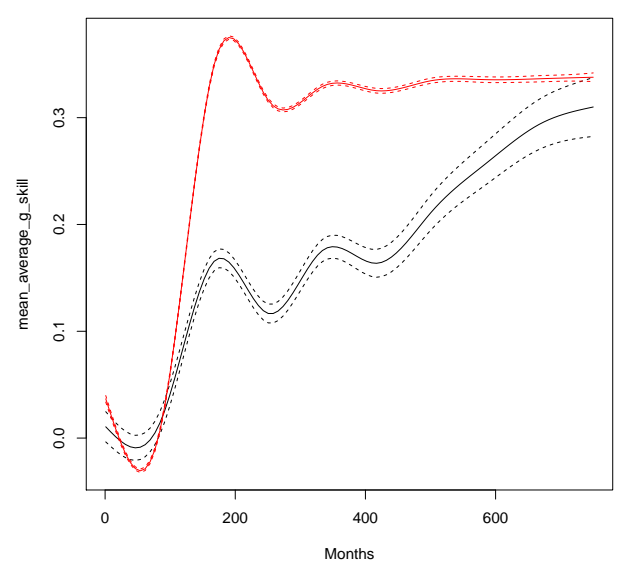

(b)

Figure 6: The relative effect of the human capital policy on (a) vintage choice and (b) general skill mix, computed as the effect on the ratio of variable values from Region 2 to that from Region 1 (black line: integrated labor market, red line: separated labor markets).

in the region at which the policy is targeted for integrated labor markets (Figure 8 (a)). The observation that due to labor flows a policy improving the general skills of (local) inhabitants might have negative effects on growth in regions where productivity is relatively small is consistent with empirical results reported in Aghion et al. (2009).

Summarizing, we observe that the HC-policy only has the intended effect of fostering convergence if the spatial labor market frictions are large. In case that labor is mobile across borders the policy has detrimental effects for the target region 2 with respect to output and technological development since the indirect negative effect stemming from the deterioration of the relative competitiveness of region 2 firms dominates the direct positive effect on vintage choices induced by the skill upgrading of the local labor force.

\subsection{Effect of Technology Policy}

Quite a different picture emerges compared to our discussion in the previous subsection if we consider the implications of the Tech-policy. Under the Techpolicy a firm which invests in physical capital of the highest vintage that is

quality of the capital stock of a firm. It is computed as a weighted sum of the capital with vintage specific productivities $A^{v}$ used as weights, i.e. $\sum_{v=1}^{V_{t}} A^{v} K_{i, t}^{v}$. 


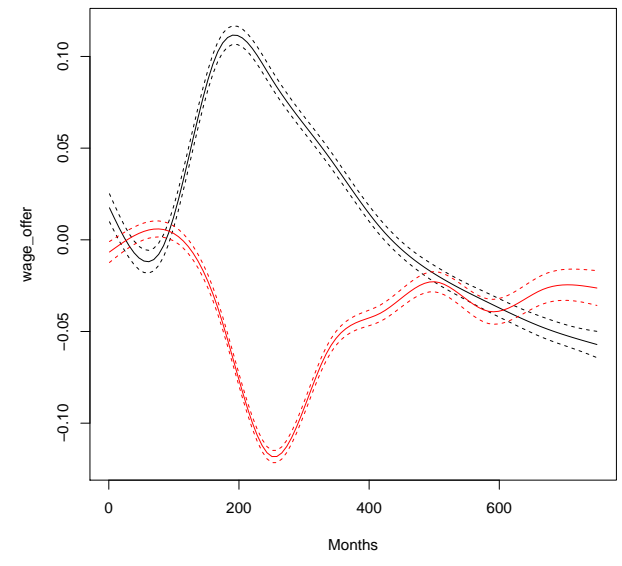

(a)

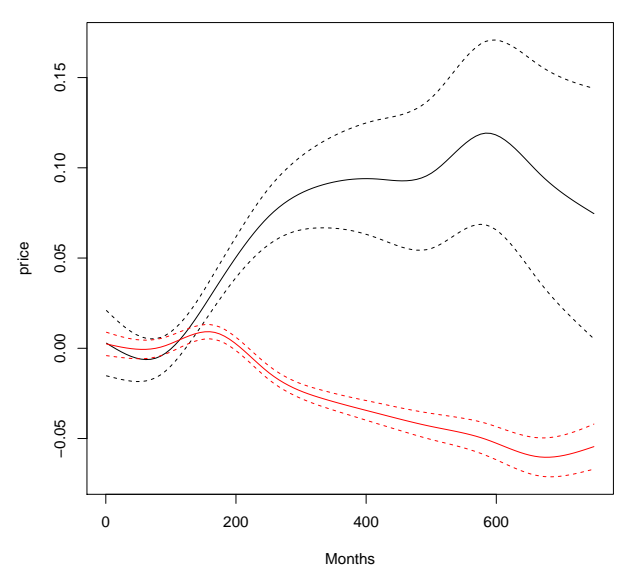

(c)

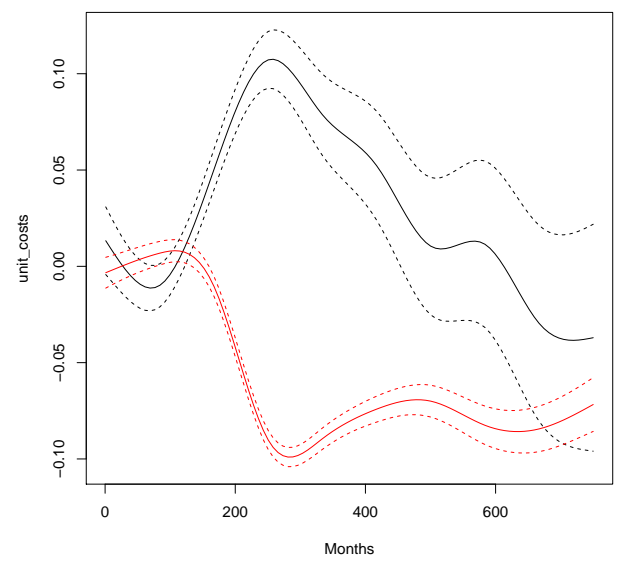

(b)

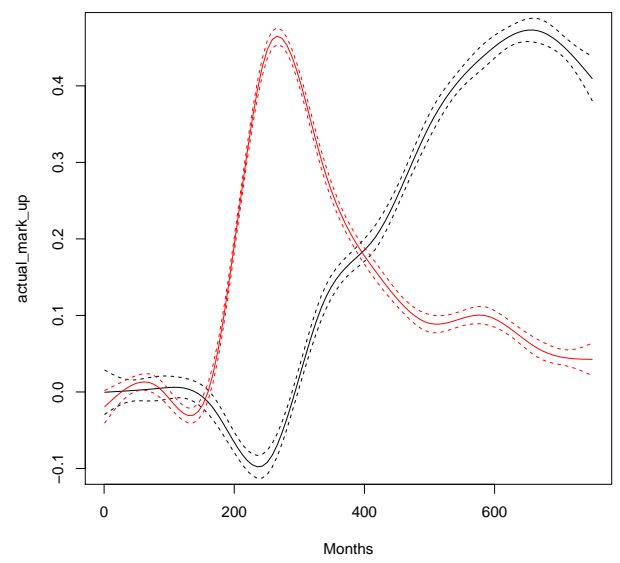

(d)

Figure 7: The relative effect of the human capital policy on (a) base wage offers, (b) unit costs, (c) prices and (d) mark ups, computed as the effect on the ratio of variable values from Region 2 to that from Region 1 (black line: integrated labor market, red line: separated labor market) 


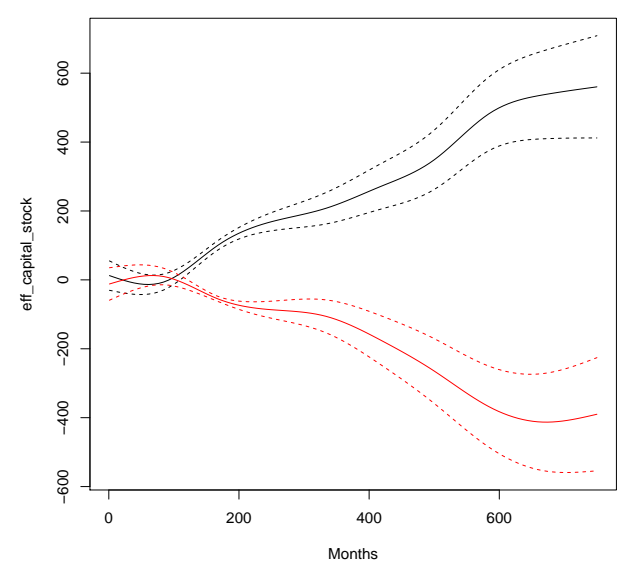

(a)

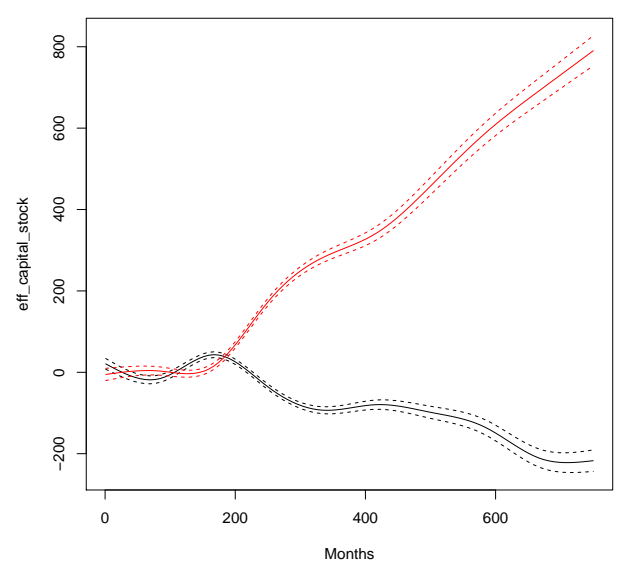

(b)

Figure 8: The effect of the human capital policy on the productivity weighted capital stocks for (a) integrated labor markets, (b) separated labor markets (black line: R1, red line: R2).

available at the time of the purchase receives a public subsidy in the amount of $5 \%$ of its investment. When deciding about their vintage choice firms take that subsidy into account. In their vintage choice rule the price is reduced for the vintage on the frontier accordingly. This distorts the vintage choice of firms in the target region in favor of the best available vintage. As can be seen in Figure 9, a targeted technology policy, leads to an increase in output produced in region 2, no matter whether the labor market is integrated or separated. The effect is much stronger if labor markets are integrated and and in this scenario there is a significant negative effect on output in region 1 , which is not present under separated labor markets.

For separated labor markets the effects of the Tech-policy is qualitatively very similar to the effect of the HC-policy. The two policies are close substitutes. This holds not only for the output dynamics, but also for variables like quality of capital, vintage choice and price. In our discussion we will, therefore, concentrate on the effects of the Tech-policy under integrated labor markets.

Figure 10 shows for this scenario the implications of the introduction of a Tech-policy for the dynamics of ratios between region 2 and region 1 for vintage choice, average quality of capital, general skills, as well as the average price of the consumption goods. The direct effect of the policy, namely an increase in the vintage choice of firms in region 2, can be clearly seen in panel (a) of this figure. In particular, this figure shows that the vintage choice in 


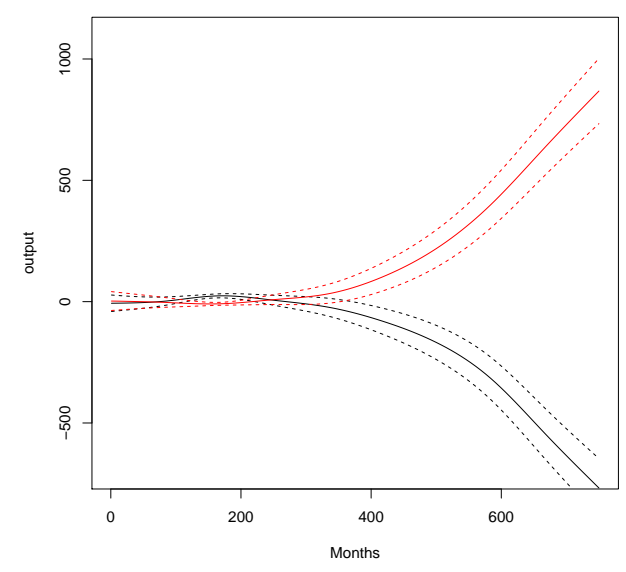

(a)

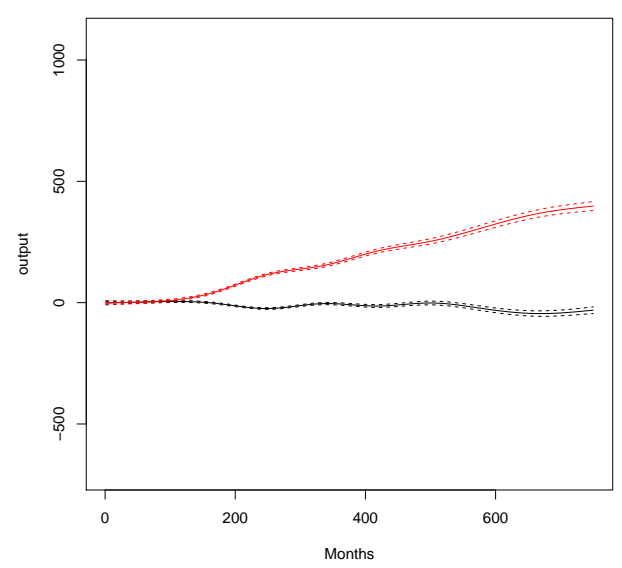

(b)

Figure 9: Effect of the Tech-policy on output in region 1 (black line) and region 2 (red line) for (a) integrated labor markets and (b) separated labor markets.

region 2 goes up relative to that of region 1, which means that the gap in terms of quality of newly acquired machines is reduced. As shown in panel (b) this results in an increase in the relative quality of the capital stock used by firms in region 2. The improvement of the quality of the capital stock induces that firms in region 2 are better able to keep workers with high general skills in their region (see panel (c)), such that the technology policy also has a positive effect on the human capital stock in region 2. In particular, this policy although not explicitly targeted at human capital upgrading, is able to improve the level of human capital employed in region 2 relative to region 1. Also in this respect the policy performs better than the HC-policy whose explicit aim is to improve the human capital endowment in region 2 . The improved quality of physical and human capital employed in region 2 leads to a reduction in the price gap between the two regions (panel (d)) and thereby improves the competitiveness of region 2 leading to the observed positive effect on output produced by region 2 firms. The higher competitiveness of region 2 comes at the expense of firms in region 1, whose output actually goes down. Considering the isolated effect of the policy on region 1 variables shows a negative effect on vintage choice and average capital quality for that region, which is due to the increase in attractiveness of high vintages for region 2 firms, thereby inducing an increase in relative prices of these vintages.

The technology policy considered in our analysis so far is targeted, in a sense that firms only receive price subsidies if they acquire the highest 


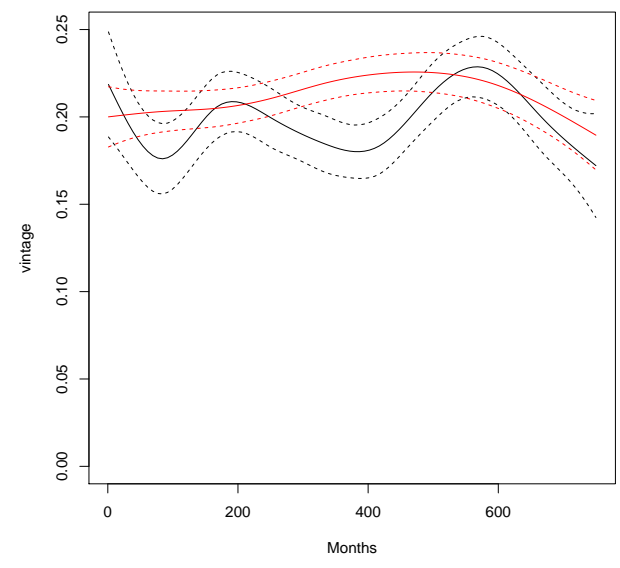

(a)

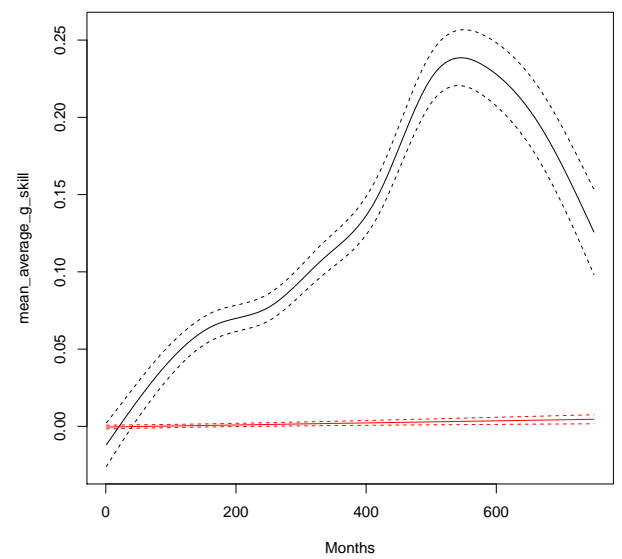

(c)

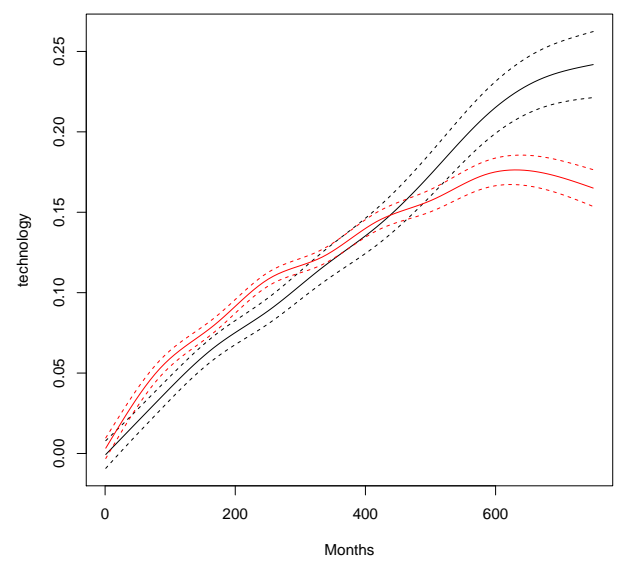

(b)

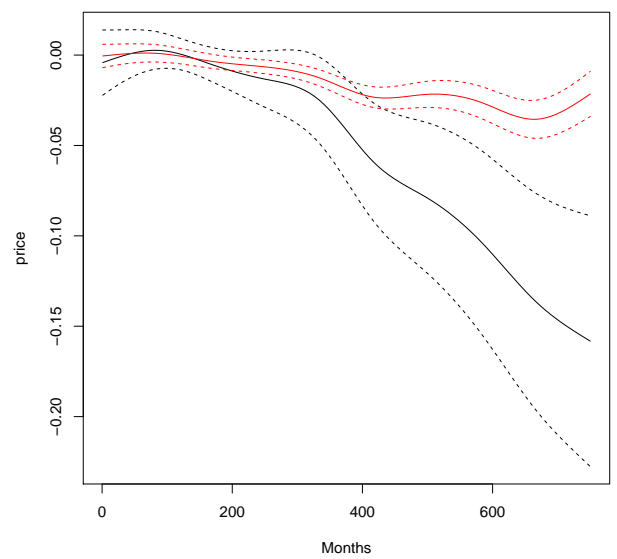

(d)

Figure 10: The relative effect of the technology policy on (a) vintage choice and (b) average quality of the capital stock and (c) general skills of workers employed in a region and (d) average price posted by firms, computed as the the effect on the ratio of variable values from Region 2 to that from Region 1 (black line: integrated labor market, red line: separated labor market) ï¿œ 


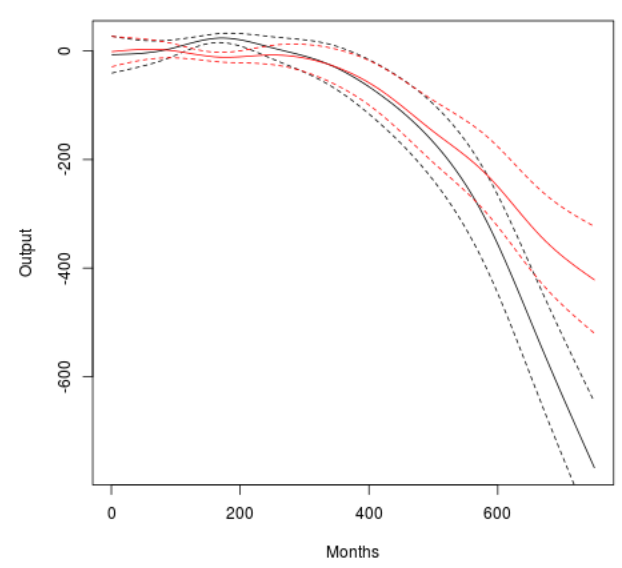

(a)

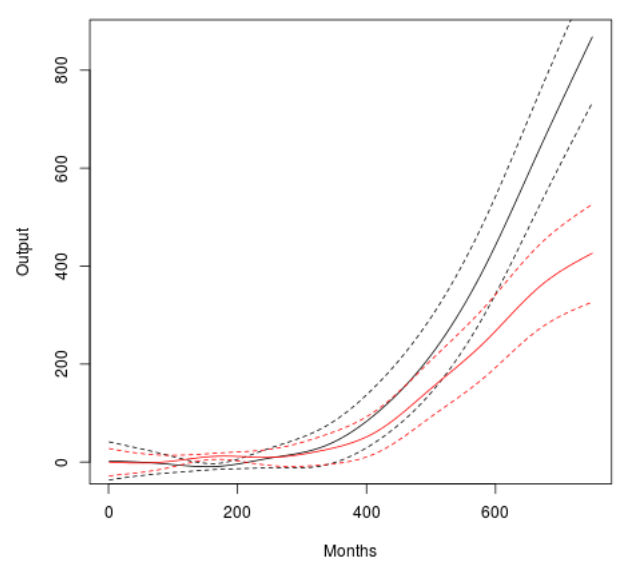

(b)

Figure 11: Comparison of the effect of the targeted (black line) and nontargeted (red line) Tech-policy on output in (a) region 1 and (b) region 2, for integrated labor markets.

available vintage. In practice such a targeted policy might be difficult to implement, since it is not easily verifiable whether an acquired machine is indeed at the technological frontier of the considered industry. Hence, one might wonder whether it is essential that price subsidies are targeted to the best vintages. Similarly to the considered Tech-policy general investment subsidies could be introduced, where firms receive a $5 \%$ subsidy on all acquisitions of physical capital. Such a measure should foster investment, thereby inducing a faster diffusion of new technologies, as well as reduce firms' unit costs and costs of expansion, which should lead to lower prices and larger output by region 2 firms. Figure 11 shows however that such a policy has a much weaker effect on output in both regions. In the absence of the stimulation of high vintage choices in region 2 the quality of capital does not increase as much as under the targeted technology policy and the fraction of high skilled workers in the region is not as high. The competitive disadvantage of region 2 with respect to unit costs, which can be completely eliminated with a targeted technology policy is reduced but not eliminated with an untargeted version of the policy 10 This shows that it is indeed important that investment subsidies are targeted in a way that the incentives of firms to acquire new vintages are increased.

\footnotetext{
${ }^{10}$ The time series data from simulations backing these observations are available from the authors on request.
} 


\subsection{Robustness of Qualitative Findings}

Our discussion of the effects of the HC and the Tech-policy was based on simulations carried out for our default parameter setting and two labor market scenarios, namely $c=0.05$ and $c=1$. We have carried out substantial robustness checks to confirm that the qualitative findings stay intact also if we vary the parameters within a reasonable range. The robustness of the results with respect to changes in the most important parameters are briefly discussed in this subsection.

In Figure 12 we show the spline estimates of the evolution of output without policy, of the impact of the HC policy, and the impact of the Techpolicy in the two regions for values of the commuting costs varying between $c=0.05$ and $c=0.5$. We restrict attention to this interval because $c=0.5$ corresponds already to a de-facto separated labor market, and hence there are virtually no effects of varying $c$ in the interval $[0.5,1]$. To keep the graphs readable we abstain from showing the standard deviations for the shown spline estimates. From panels (a) and (b) it can be clearly seen that in the absence of policies the output in region 1 is monotonically decreasing and output in region 2 monotonously increasing with respect to the commuting costs for any considered time $t$, but the effect becomes much more pronounced in the long run. Considering the effect of the HC-policy the figure shows that the negative implications of the policy in the target region for the case of integrated labor markets apply to values of the commuting costs up to approximately $c=0.15$. In this range the effect for region 1 is positive as discussed above. Only for commuting costs above this level is region 2 positively affected by the policy, where the positive effects is strongest for a scenario where spatial labor market frictions are considerable, but markets are not fully separated. Also the qualitative findings concerning the effects of the Tech-policy are confirmed. The effect is positive in region 2 and negative in region 1, where the sizes of these effects decrease as spatial labor market frictions increase.

We have carried out numerous robustness checks with respect to variations of other parameters, in order to check whether the key qualitative findings - in particular the observations that the HC-policy has negative effects for integrated and positive effects for separated labor markets in the target region, whereas effects of the Tech-policy are always positive - stay intact. Robustness of this kind could be confirmed for all considered parameters. In the Appendix we present such robustness checks for two additional key parameters, which have been identified as most influential for the characteristics of the simulation runs. 


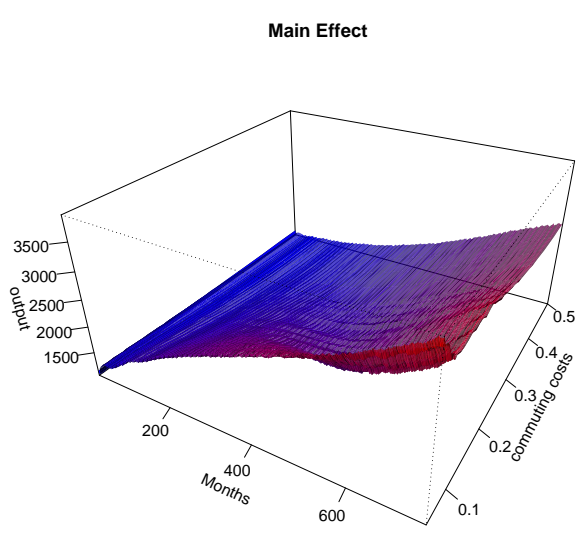

(a)

HC Effect

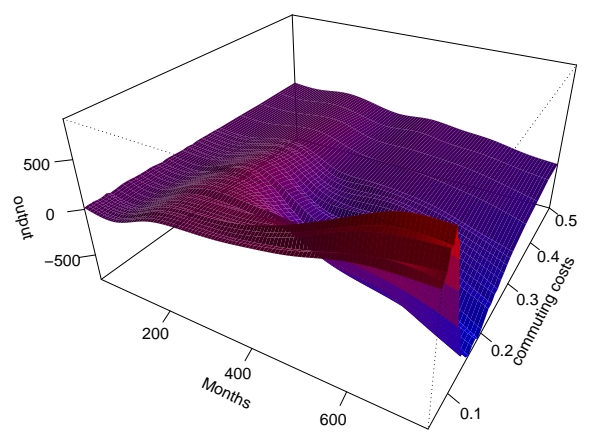

(c)

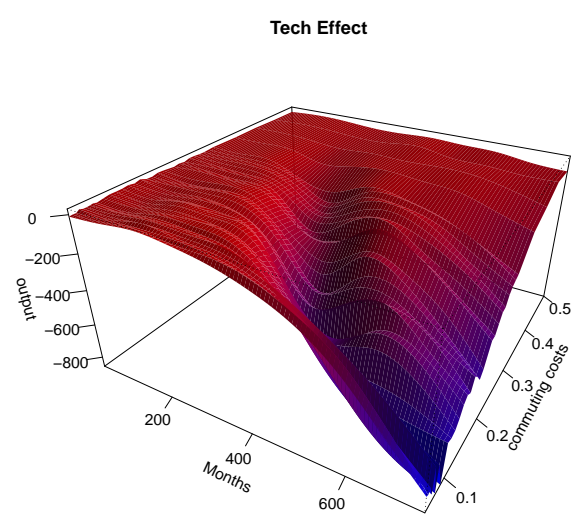

(e)

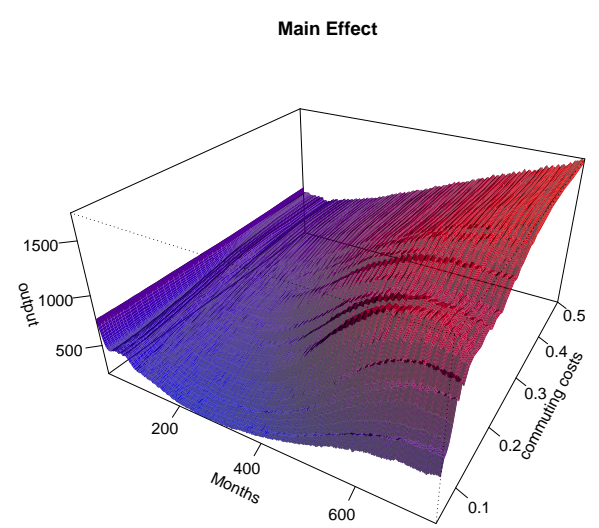

(b)

HC Effect

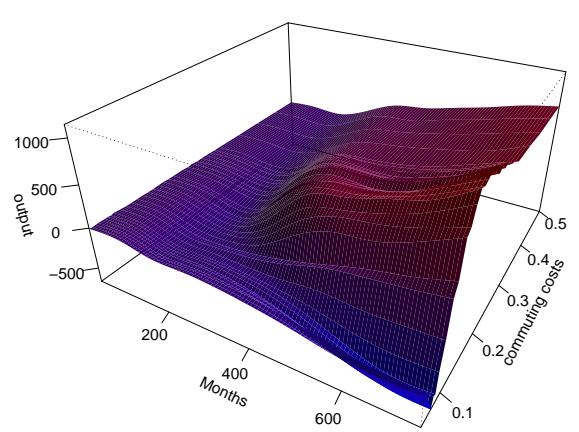

(d)

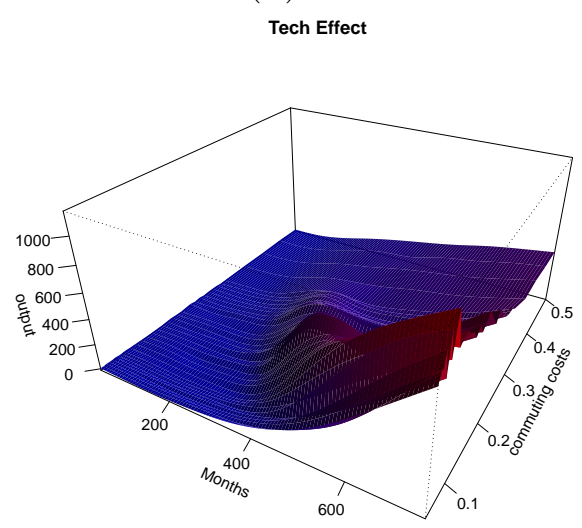

(f)

Figure 12: Effects of a variation of commuting costs on the evolution of output ((a) and (b)), the effectiveness of the human capital policy ((c) and $(\mathrm{d}))$, and the effectiveness of the technology policy ((e) and (f)) in Region 1 (left column) and Region 2 (right column). 


\section{Discussion and Conclusion}

In this paper we have used the agent-based macroeconomic Eurace@Unibi model to analyze in how far two types of cohesion policies, which are inspired by measures applied by the European Union, are suitable to foster convergence between regions that differ with respect to their initial endowments in the quality of physical and human capital. We have shown that both types of policies have the intended effects as long as labor is sufficiently immobile. With integrated labor markets the human capital policy has detrimental output effects for the region at which the policy is targeted. Technology policy, implemented through subsidies for acquisition of physical capital is effective, and particularly so if the subsidy is targeted and only paid if firms invest in vintages at the technological frontier.

We have explored the mechanisms underlying the different policy effects and shown that these effects are driven by the interplay of firms' vintage choices and investment decisions. While the former is a straightforward and expected outcome of the policies, the latter is the product of an economic mechanism resulting from the cohesion policies that affect the evolution of relative output through changes in regions' competitiveness which in turn result from the dynamics of the (general and specific) skill levels of workers in the two regions. It turns out that for HC-policies the indirect effect on investments arising through the reduction in the regions' competitiveness is so strong that the policy has a negative effect on (productivity weighted) capital stock and output in the target region for integrated labor markets.

To put these findings into perspective it should be pointed out that firms in the two regions are actually identical in many respects. The firms share the same production functions, households share the same rules determining their savings, their consumption decision etc. and apart from the subsidies introduced in the framework of the Tech-policy the public (fiscal) policies are the same in both regions. In the baseline scenario the two regions differ only with respect to the initial quality of the physical capital stock, with respect to the initial distribution of specific skills in the two regions and with respect to the general skill distributions. Since the first two of these three items refer to initial values of endogenous variables of the model, the only structural difference between the two regions is the difference with respect to general skills.

This asymmetry disappears once the HC-policy, which makes the general skill distribution in region 2 equal to that of region 1, is introduced. Considering the long run equilibrium balanced growth path of this two-region economy one would therefore expect that regardless of the spatial labor market frictions the two regions grow at the same rate. Furthermore, according 
to such an analysis, the effect of the HC-policy would always be positive for region 2 regardless of the amount of labor market frictions. The analysis in this paper also takes into account the short and medium run implications of the policies, which arguably for many issues is the most relevant time-frame for policy evaluation, and we obtain much richer and more differentiated insights into the effects of the considered policy measures. In particular, the fact that the economic dynamics of the two regions is explicitly simulated allows to capture path dependencies, which in this framework are crucial for the understanding of the policy implications in the different considered scenarios. These path dependencies, which hinge on the interplay of firms' stocks of physical and human capital with their vintage choices, investment decisions and worker movements between firms, generate obstacles to overcome the initial regional asymmetry and leads to a diversion of positive policy effects from the target region toward the high tech region 1. Overall, these findings illustrate the merits of an agent-based approach for the analysis of effects of different policy measures and their combination in different time-frames.

More broadly speaking, from the policy perspective our results suggest that distinct policies aiming to speed up convergence are offsetting each other. As we have shown, the HC-policy and the Tech-policy are more effective with respect to achieving convergence if labor markets are not integrated. This insight from our model squares well with findings from the empirical literature on the effect of EU funding. While there does not seem to be a clear-cut picture emerging from empirical studies, as we outlined earlier on, there seems to be evidence that EU policies may foster convergence between countries while they rather fail to spur convergence between regions. Interpreting the differences between countries and regions as workers being more mobile between regions and less mobile between countries, this part of the empirical evidence on the effects of EU policies is what our model predicts for HC-policies. Thus policies, that target the improvement of labor mobility between regions may render policies targeting the cohesion of regions ineffective.

\section{A Appendix}

\section{A.1 Robustness Checks}

In this appendix we show the robustness of our findings with respect to a variation of two specific parameters of the model, which both have a considerable impact on the simulation outcome. The two parameters, the price sensitivity of consumers and the speed of change of the technological frontier, have been identified in extensive experiments with the model as the 
parameters that have the largest impact on the qualitative properties of the simulation dynamics. Hence we report our robustness checks with respect to these two parameters here. Additional robustness checks for other parameters have been done but effects of parameter variations turned out to be much weaker.

The first considered parameter specifies the price sensitivity in the consumption choice problem of households. The decision which good to purchase is modeled as a logit model where the probability to buy a particular good depends on its relative price. The weight of the price in the logit function, which can also be interpreted as the intensity of choice, is given by the parameter $\gamma^{C}$. Varying this parameter changes the strength of how households react to price changes and thus it determines the scope for price changes of individual firms and the overall competitiveness on the consumption goods market. In the experiment we use a value of $\gamma^{C}=9.0$ that is associated with a medium level of competitiveness. For the robustness check this parameter is varied within a range between 7.0 and 11.0, which is a range in accordance with empirical estimations obtained for consumption good markets (see Krishnamruthi and Raj (1988)). Figure 13 shows how the variation of this parameter affects the evolution of the regional output in the initially less developed region 2 and how the variation of the parameter influences the effectiveness of the human capital and technology policy in this region. It can be clearly seen that the qualitative features worked out for the default parameter setting, namely that the effect of the HC-policy is negative for integrated and positive for separated labor markets, whereas the effect of the Tech-policy is positive in both labor market scenarios stay intact for the entire considered range of the parameter $\gamma^{C}$. An interesting additional observation is that the size of the negative respectively positive impact of the policies under an integrated labor market goes down if the consumption good market becomes more competitive. The intuition for this observation is that in such a strongly competitive environment the weaker region 2 shows almost no growth without policy (see panel (a)), which, on the one hand, means that there is little to lose by the ill-suited application of the HC-policy. On the other hand, even with the help of the Tech-policy, the growth in region 2 is very slow in the presence of the intensive competition of firms from region 1.

The second parameter with a strong impact on the simulations is the speed of technological change. As described in Section 3.2.4 the development of improved capital goods is the result of a stochastic process, where with an exogenously given probability a new vintage emerges whose productivity is improved by $\Delta q^{i n v}$ compared to the previous best practice technology. In the experiments, we use identical realizations of the stochastic innovation process in order to avoid spurious growth effects due to different dynamics 
of the frontier. To check the robustness of the policy analysis with respect to different speeds of technological growth, we keep using the same realization of the stochastic process determining the period when innovations take place, but vary the parameter for the productivity progress $\Delta q^{i n v}$ at each innovation step within a range of 0.0 and 0.07 . Thereby, a value of 0.0 means no technological progress. In the policy experiments we use a value of 0.05 that translates to an average productivity growth of the frontier by $1.8 \%$ per annum. Figure 14 shows the impact on the output evolution and the policy effectiveness in region 2. Again, it can be clearly seen that all qualitative effects of the policies in the entire interval correspond to those observed in our default setting. 


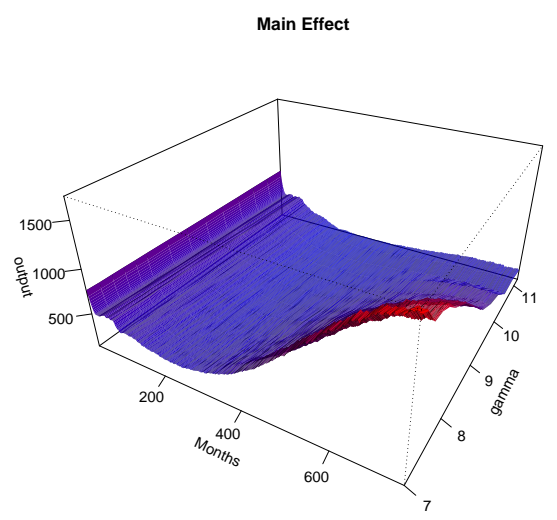

(a)

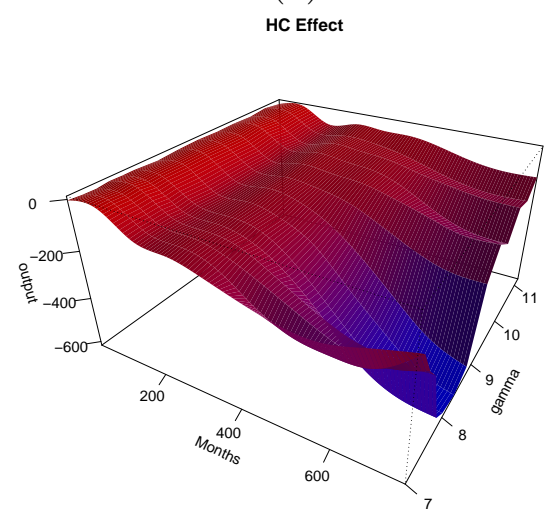

(c)

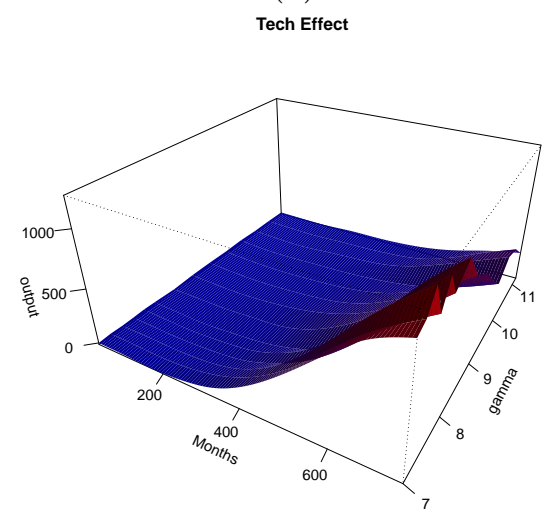

(e)

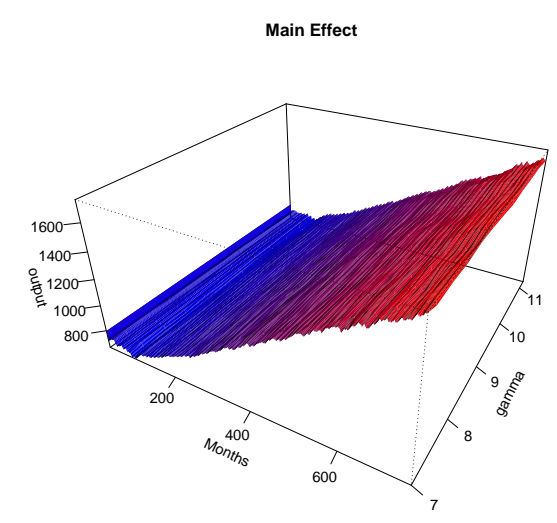

(b)

HC Effect

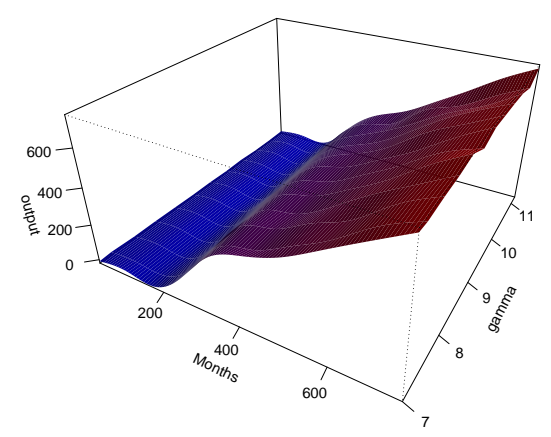

(d)

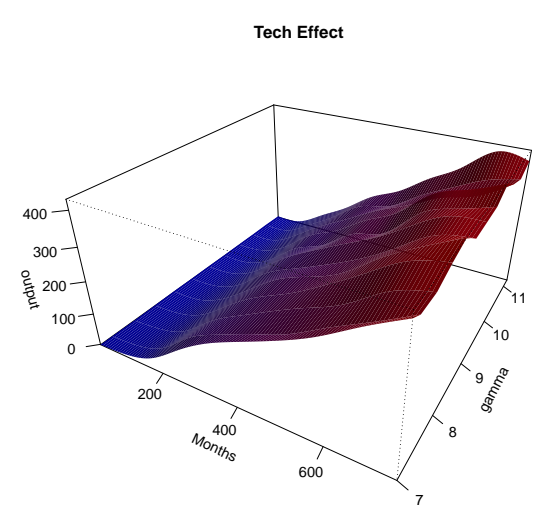

(f)

Figure 13: Effects of a variation of households' price sensitivity on the evolution of output without policy ((a) and (b)), the effectiveness of the human capital policy ((c) and (d)), and the effectiveness of the technology policy ((e) and (f)) in the lagging Region 2 for integrated (left column) and separated (right column) labor markets. 


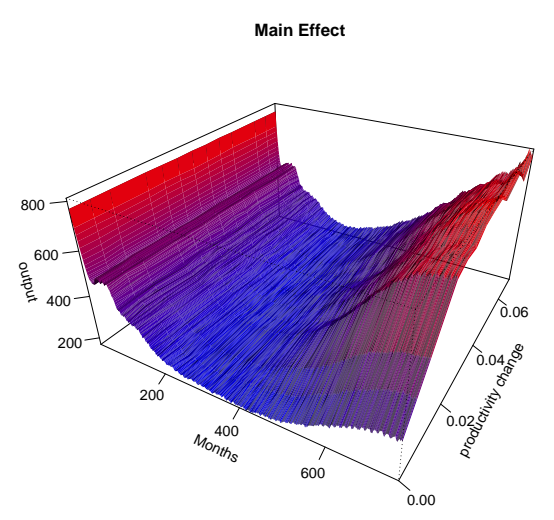

(a)

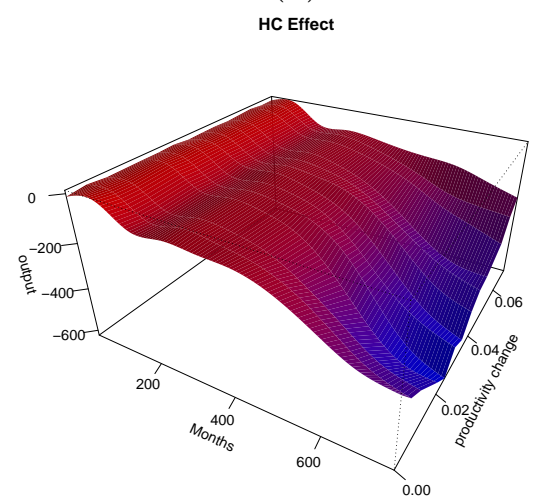

(c)

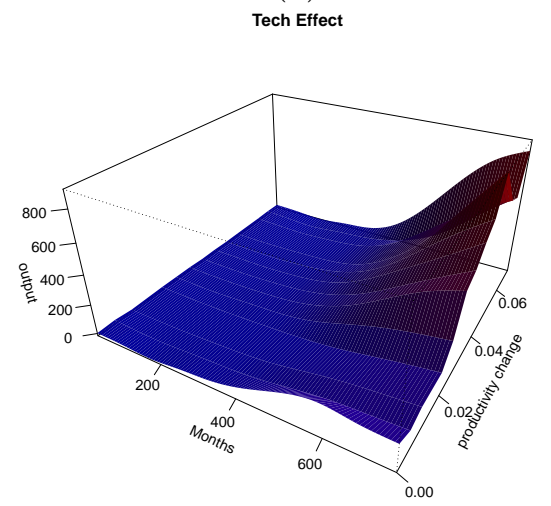

(e)

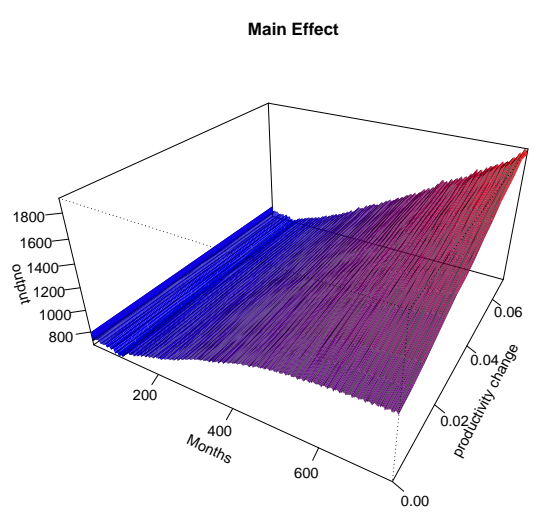

(b) HC Effect

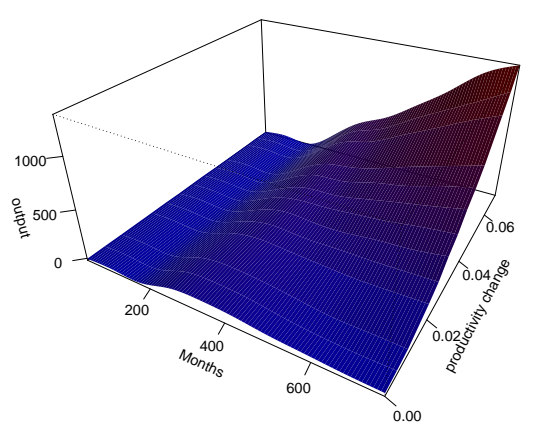

(d)

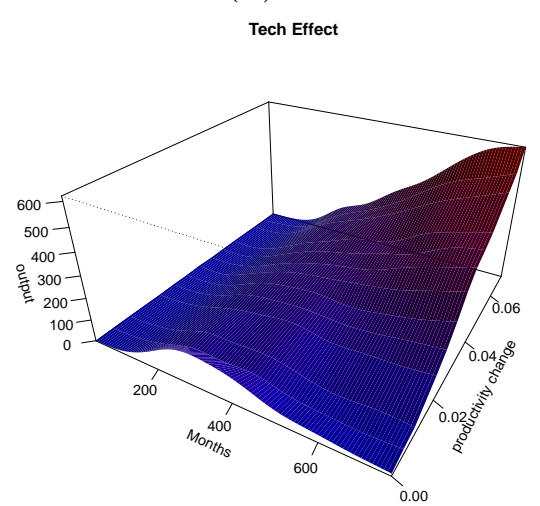

(f)

Figure 14: Effects of a variation of the speed of technological change on the evolution of output without policy ((a) and (b)), the effectiveness of the human capital policy ((c) and (d)), and the effectiveness of the technology policy ((e) and (f)) in the lagging Region 2 for integrated (left column) and separated (right column) labor markets. 


\section{References}

Acemoglu, D. (1998): "Why do new technologies complement skills? Directed technical change and wage inequality," The Quarterly Journal of Economics, 113, 1055-1089.

Acemoglu, D. And F. Zilibotti (2001): "Productivity differences," The Quarterly Journal of Economics, 116, 563-606.

Aghion, P., L. Boustan, C. Hoxby, And J. Vandenbussche (2009): "The causal impact of education on economic growth: evidence from U.S." Harvard University, mimeo.

Aiello, F. And V. Pupo (2012): "Structural funds and the economic divide in Italy," Journal of Policy Modeling, 34, 403-418.

Allen, T. And C. Carroll (2001): "Individual learning about consumption," Macroeconomic Dynamics, 5, 255-271.

Arcalean, C., G. Glomm, and I. Schiopu (2012): "Growth effects of spatial redistribution policies," Journal of Economic Dynamics and Control, 36, 988-1008.

Argote, L. And D. Epple (1990): "Learning curves in manufacturing," Science, 247, 920-924.

Arifovic, J., J. Bullard, And O. Kostyshyna (2012): "Social learning and monetary policy rules," The Economic Journal, DOI: 10.1111/j.14680297.2012.02525.x.

Ashraf, Q., B. Gershman, And P. Howitt (2011): "Banks, Market Organization, and Macroeconomic Performance: An Agent-Based Computational Analysis," NBER working paper 17102.

(2012): "How Inflation Affects Macroeconomic Performance: An Agent-Based Computational Investigation," NBER working paper 18225.

BASU, S. AND D. N. WeIL (1998): "Appropriate technology and growth," The Quarterly Journal of Economics, 113, 1025-1054.

Becker, S. O., P. H. Egger, And M. von Ehrlich (2010): "Going NUTS: The effect of EU structural funds on regional performance," Journal of Public Economics, 94, 578-590. 
Beugelsdijk, M. And S. EiJfFinger (2005): "The effectiveness of structural policy in the European Union: an empirical analysis for the EU-15 in 1995-2001," Journal of Common Market Studies, 43, 207-253.

Boldrin, M. And F. Canova (2001): "Inequality and convergence in Europe's regions: reconsidering European regional policies," Economic Policy, 16, 206-245.

Cappelen, A., F. Castellaci, J. Fagerberg, and B. Verspagen (2003): "The impact of regional support on growth and convergence in the European Union," Journal of Common Market Studies, 41, 621-644.

CARroll, C. (1997): "Buffer-stock saving and the life cycle/permanent income hypothesis," The Quarterly Journal of Economics, 112, 1-55.

Caselli, F. And W. Coleman (2006): "The world technology frontier," American Economic Review, 96, 499-522.

Comin, D. And B. Hobijn (2010): "An exploration of technology diffusion," American Economic Review, 100, 2031-2059.

(2011): "Technology Diffusion and Postwar Growth," Harvard Business School, Working Paper 11-027.

Dawid, H., S. Gemkow, P. Harting, And M. Neugart (2012a): "Labor market integration policies and the convergence of regions: the role of skills and technology diffusion," Journal of Evolutionary Economics, 22, $543-562$.

Dawid, H., S. Gemkow, P. Harting, S. van der Hoog, and M. NeuGART (2012b): "The Eurace@Unibi Model: An Agent-Based Macroeconomic Model for Economic Policy Design," Report, Bielefeld University: http://www.wiwi.uni-bielefeld.de/fileadmin/vpl1/Publications/Agentbased_Modelling/eurace_unibi_descr_2012.pdf.

Dawid, H. And P. Harting (2012): "Capturing Firm Behavior in AgentBased Models of Industry Evolution and Macroeconomic Dynamics," in Applied Evolutionary Economics, Behavior and Organizations, ed. by G. Bünsdorf, Edward-Elgar, 103-130.

Delli Gatti, D., M. Gallegati, B. Greenwald, A. Russo, And J. Stiglitz (2010): "The financial accelerator in an evolving credit network," Journal of Economic Dynamics and Control, 34, 1627-1650. 
Dosi, G., G. Fagiolo, And A. Roventini (2010): "Schumpeter meeting Keynes: a policy-friendly model of endogenous growth and business cycles," Journal of Economic Dynamics and Control, 34, 1748-1767.

Dosi, G., F. Malerba, O. Marsili, and L. Orsenigo (1997): "Industrial structures and dynamics: evidence, interpretations and puzzles," Industrial and Corporate Change, 6, 3-24.

Ederveen, S., L. F. H. De Groot, and R. Nahuis (2006): "Fertile soil for structural funds? A panel data analysis of the conditional effectiveness of European cohesion policy," Kyklos, 59, 17-42.

European Commission (2006): "Employment in Europe 2006," Report from the Commission.

(2011): "Employment and Social Development in Europe 2011," Report from the Commission.

Fabiani, S., M. Druant, I. Hernando, C. Kwapil, B. Landau, C. Loupias, F. Martins, T. Matha, R. Sabbatini, H. Stahl, and A. Stokman (2006): "What firm surveys tell us about price-setting behavior in the euro area," International Journal of Central Banking, 2, 3-47.

Gintis, H. (2007): "The dynamics of general equilibrium," Economic Journal, 117, 1280-1309.

ISLAM, N. (2003): "What have we learnt from the convergence debate?" Journal of Economic Surveys, 17, 309-362.

Kauermann, G., G. Claeskens, and J. D. Opsomer (2009): "Bootstrapping for penalized spline regression," Journal of Computational and Graphical Statistics, 18, 126-146.

Krishnamruthi, L. And S. P. RAJ (1988): "A model of brand choice and purchase quantity price sensitivities," Marketing Science, 7, 1-20.

Krivobokova, T. And G. Kauermann (2007): "A note on penalized spline smoothing with correlated errors," Journal of the American Statistical Association, 102, 1328-1337.

Malhotra, N. (1984): "The Use of Linear Logit Models in Marketing Research," Journal of Marketing research, 11, 20-31.

Mateos-Planas, X. (2001): "Schooling and distortions in a vintage capital model," Review of Economic Dynamics, 4, 127-158. 
Nagle, T. And J. Hogan (2006): The Strategy and Tactics of Pricing: A Guide to Growing More Profitably, New Jersey: Pearson Prentice Hall.

PARENTE, S. L. (1994): "Technology adoption, learning-by-doing, and economic growth," Journal of Economic Theory, 63, 346-369.

Parente, S. L. And E. C. Prescott (1994): "Barriers to technology adoption and development," Journal of Political Economy, 102, 298-321.

Piva, M. AND M. Vivarelli (2009): "Corporate skills as an ex-ante incentive to R\&D investment," International Journal of Manpower, 30, 835-852.

Raberto, M., A. Telgio, and S. Cincotti (2012): "Debt, deleveraging and business cycles: an agent-based perspective," Economics, The OpenAccess, Open-Assessment E-Journal, 6.

Ramajo, J., M. A. Marquez, G. J. D. Hewings, and M. M. Salinas (2008): "Spatial heterogeneity and interregional spillovers in the European Union: do cohesion policies encourage convergence across regions?" European Economic Review, 52, 551-567.

Silver, E., D. Pyke, And R. Peterson (1998): Inventory Management and Production Planing and Scheduling, John Wiley \& Sons.

Stock, J. And M. WATson (1999): "Business cycle fluctuations and U.S. macroeconomic time series," in Handbook of Macroeconomics, Vol. 1, ed. by J. Taylor and M. Woodford, Amsterdam: Elsevier, 3-64.

Wolf, S., S. Fuerst, A. Mandel, W. Lass, D. Lincke, F. PabloMARTI, AND C. JAEGER (2012): "Lagom regiO - a multi-agent model of several economic regions," to appear in: Proceedings of the 100th Dahlem Conference, New Approaches in Economics after the Financial Crisis.

Wood, S. (2011): "Fast stable restricted maximum likelihood and marginal likelihood estimation of semiparametric generalized linear models," Journal of the Royal Statistical Society, 73, 3-36. 